\title{
Effects of Ibotenate and 192IgG-Saporin Lesions of the Nucleus Basalis Magnocellularis/Substantia Innominata on Spontaneous Sleep and Wake States and on Recovery Sleep after Sleep Deprivation in Rats
}

\author{
Satvinder Kaur, Adrienne Junek, Michelle A. Black, and Kazue Semba \\ Department of Anatomy and Neurobiology, Faculty of Medicine, Dalhousie University, Halifax, Nova Scotia B3H 1X5, Canada
}

\begin{abstract}
The basal forebrain $(\mathrm{BF})$ is known for its role in cortical and behavioral activation, and has been postulated to have a role in compensatory mechanisms after sleep loss. However, specific neuronal phenotypes responsible for these roles are unclear. We investigated the effects of ibotenate (IBO) and 192IgG-saporin (SAP) lesions of the caudal BF on spontaneous sleep-waking and electroencephalogram (EEG), and recovery sleep and EEG after $6 \mathrm{~h}$ of sleep deprivation (SD). Relative to artificial CSF (ACSF) controls, IBO injections decreased parvalbumin and cholinergic neurons in the caudal BF by 43 and $21 \%$, respectively, and cortical acetylcholinesterase staining by $41 \%$. SAP injections nonsignificantly decreased parvalbumin neurons by $11 \%$, but significantly decreased cholinergic neurons by $69 \%$ and cortical acetylcholinesterase by $84 \%$. IBO lesions had no effect on sleep-wake states but increased baseline delta power in all states [up to $62 \%$ increase during non-rapid eye movement (NREM) sleep]. SAP lesions transiently increased NREM sleep by $13 \%$, predominantly during the dark phase, with no effect on EEG. During the first $12 \mathrm{~h}$ after SD, animals with IBO and SAP lesions showed lesser rebound NREM sleep (32 and 77\% less, respectively) and delta power (78 and 53\% less) relative to ACSF controls. These results suggest that noncholinergic BF neurons promote cortical activation by inhibiting delta waves, whereas cholinergic BF neurons play a nonexclusive role in promoting wake. Intriguingly, these results also suggest that both types of BF neurons play important roles, probably through different mechanisms, in increased NREM sleep and EEG delta power after sleep loss.
\end{abstract}

Key words: basal forebrain; ibotenic acid; 192 IgG-saporin; EEG; waking; recovery sleep

\section{Introduction}

The basal forebrain (BF) plays a role in cortical activation and behavioral arousal (Semba, 2000; Jones, 2005) as part of the forebrain circuitry responsible for behavioral state control. Singleunit studies have shown prevalence of BF neurons that increase firing during cortical electroencephalogram (EEG) activation and wake state (Detari et al., 1999; Szymusiak et al., 2000; Jones, 2005) and increased waking and EEG activation after pharmacological activation of BF neurons (Manfridi et al., 1999; Cape and Jones, 2000). These studies, however, did not discriminate BF neurons with different transmitter phenotypes. The BF contains cholinergic, GABAergic, and putative glutamatergic neurons that project to the cortex and reticular thalamic nucleus, areas in-

\footnotetext{
Received April 9, 2007; revised Dec. 1, 2007; accepted Dec. 1, 2007.

This work was supported by grants from the Canadian Institutes of Health Research (MOP14451). A.J. held a Killam Predoctoral Scholarship, and M.A.B. held a Natural Science and Engineering Research Council Predoctoral Award. We thank Joan Burns for her excellent technical assistance, Stephen Whitefield and Angela Gamouras for their advice on imaging analysis, and Drs. Samuel Deurveilher and Doug Rasmusson for a critical reading of a previous version of this manuscript.

Correspondence should be addressed to Kazue Semba, Department of Anatomy and Neurobiology, Faculty of Medicine, Dalhousie University, 5850 College Street, Halifax, Nova Scotia B3H 1X5, Canada. E-mail: semba@dal.ca.

S. Kaur's present address: West Roxbury Veterans Affairs Medical Center and Harvard Medical School, Building 3, Laboratory 2c109, 1400 VFW Parkway, West Roxbury, MA 02132. E-mail: satvinder_kaur@hms.harvard.edu.

DOI:10.1523/JNEUROSCI.1585-07.2008

Copyright $\odot 2008$ Society for Neuroscience $\quad$ 0270-6474/08/280491-14\$15.00/0
}

volved in EEG regulation, and to the amygdala, hypothalamus, and brainstem, including areas involved in sleep-wake regulation (Gritti et al., 1997; Zaborszky et al., 1999). These neurochemically heterogeneous BF projections have been proposed to mediate distinct cognitive, motivational, emotional, motor, and regulatory aspects of vigilance (Semba, 2000).

To understand the role of cholinergic and noncholinergic BF neurons in sleep-wake regulation, nonselective excitotoxins, such as ibotenate (IBO), and 192IgG-saporin (SAP), an immunotoxin selective to $\mathrm{BF}$ cholinergic neurons bearing p75 nerve growth factor receptors, have been used. Nonselective BF lesions increased delta power in the EEG (Buzsaki et al., 1988; Riekkinen et al., 1990, 1991; Vanderwolf et al., 1993), whereas lesions highly selective to cholinergic neurons had relatively minor or no effect on spontaneous EEG or sleep-wake states (Bassant et al., 1995; Kapas et al., 1996; Berntson et al., 2002; Blanco-Centurion et al., 2006).

More recently, it has been postulated that the BF plays a key role in sleep homeostasis (Porkka-Heiskanen et al., 1997, 2002). This is based primarily on a sustained increase in extracellular adenosine levels selectively in the BF during prolonged wakefulness for 3-6 h (Porkka-Heiskanen et al., 1997, 2002) and increased sleep and EEG delta power after intra-BF microinjections of adenosine or a nucleoside transport inhibitor (Porkka- 
Heiskanen et al., 1997; Portas et al., 1997). The role of cholinergic BF neurons in adenosine-mediated sleep homeostasis has recently been challenged by Blanco-Centurion et al. (2006), who showed that intracerebroventricular injections of 192IgG-SAP had no effect on sleep homeostasis, although the lesion blocked an increase in adenosine levels during sleep deprivation (SD). However, infusion of an adenosine $A_{1}$ receptor agonist into the BF still increased non-rapid eye movement (NREM) sleep after SAP lesions. Together, these findings suggest that the BF and in particular its noncholinergic neurons may be involved in sleep homeostasis.

To understand the roles of noncholinergic and cholinergic BF neurons in spontaneous sleep-waking and EEG, and in homeostatic sleep regulation, we lesioned the nucleus basalis magnocellularis/substantia innominata (NBM/SI) with IBO, which has been suggested to be preferential to noncholinergic BF neurons (Cahill and Baxter, 2001; Pang et al., 2001), and with 192IgGSAP. We first investigated the effects of these lesions on spontaneous sleep and EEG for $27 \mathrm{~d}$ postlesion, and then on recovery sleep and EEG after $6 \mathrm{~h}$ of SD on day 28.

\section{Materials and Methods}

\section{Animals and surgery}

All procedures involving animals were approved by the Dalhousie University Committee of Laboratory Animals in accordance with the policies of the Canadian Council of Animal Care.

Thirty-nine male Wistar rats (250-300 g; Charles River Canada, St. Constant, Quebec, Canada) were housed under a 12:12 light:dark (L:D) cycle, with lights on at 7:00 A.M. Food and water were available ad libitum. Under surgical anesthesia with an intraperitoneal injection of a mixture of ketamine $(60 \mathrm{mg} / \mathrm{kg} / \mathrm{ml})$, xylazine $(3.2 \mathrm{mg} / \mathrm{kg} / \mathrm{ml})$, and acepromazine $(0.6 \mathrm{mg} / \mathrm{kg} / \mathrm{ml})$, the animals were implanted with EEG, electromyogram (EMG), and electrooculogram (EOG) electrodes and with stainless-steel guide cannula(e) targeting the NBM/SI region. Two pairs of stainless-steel screw EEG electrodes were in contact with the dura above the frontal and parietal cortices $[2.0 \mathrm{~mm}$ anterior (A) and $2.0 \mathrm{~mm}$ posterior $(\mathrm{P})$ to bregma; $\pm 2.0 \mathrm{~mm}$ lateral $(\mathrm{L})$ from midline] for frontoparietal recording from both hemispheres. An additional screw was embedded near the frontal suture as a ground electrode. A pair of EOG electrodes made of insulated wire exposed at the end (AS 636, Cooner Wire, Chatsworth, CA) was sutured to the extraocular muscles for bilateral (left-right) recording. A pair of EMG electrodes, also made of the same insulated wire (AS 636), was fastened through and around the nuchal muscles with uninsulated portions $(2-3 \mathrm{~mm})$ lying securely at the back of the muscles. Bilateral $(n=19)$ or unilateral $(n=20)$ stainlesssteel guide cannulas (26G; Plastics One, Roanoke, VA) were implanted such that the tip was positioned at $2.0 \mathrm{~mm}$ above the NBM/SI region (P: $1.3 \mathrm{~mm}$; L: $\pm 2.5 \mathrm{~mm}$; ventral: $5.5 \mathrm{~mm}$ ) according to Paxinos and Watson (1998). All the recording electrodes were preconnected to a nine-pin connector by fine wires, and the connector and the guide cannula fitted with stylet were anchored to the skull with dental cement.

\section{Polygraphic recordings, lesions, sleep deprivation, and perfusion} Preinjection baseline recording. After a recovery period of 7-10 d, animals were placed individually in a recording chamber made of an electrically shielded Plexiglas cage without a ceiling $\left(37.5 \times 37.5 \times 37.5 \mathrm{~cm}^{3}\right)$ that was placed in a sound-attenuated wooden chamber $(57.5 \times 45.0 \times 47.5$ $\mathrm{cm}^{3}$ ). Each recording chamber was equipped with an electric fan, a lamp (for a 12:12 L:D cycle, with lights on at 7:00 A.M., as in the animal care facility), and a video camera. Food and water were available ad libitum. Animals were placed in the recording chamber for habituation for a period of 36-40 h at least once before the baseline recording (Fig. 1). Animals were not attached to recording cables for the first $\sim 12 \mathrm{~h}$ and then connected to the cables for the rest of the habituation period. Similarly, before each subsequent recording session, animals were connected to the cables for $\sim 12 \mathrm{~h}$ for acclimatization.

A $24 \mathrm{~h}$ preinjection baseline recording started at 7:00 A.M. (lights-on)

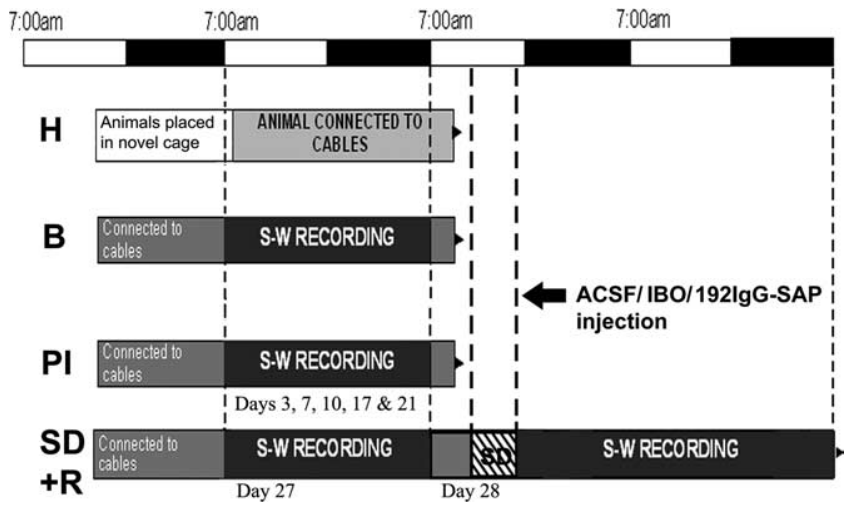

Figure 1. The experimental schedule used in the present study. The top row with open and solid bars represents 12:12 light:dark cycles, with lights on at 7:00 A.M. The following rows depict the schedule for habituation $(\mathrm{H})$, preinjection baseline $(\mathrm{B})$, postinjection $(\mathrm{PI}), \mathrm{SD}$, and recovery $(R)$ sessions. $S-W$, Sleep-wake. PI recordings were conducted on days 3, 7, 10, 17, 21, and 27 after ACSF, IB0, or 192lgG-SAP injections. SD was conducted for $6 \mathrm{~h}$ by gentle handling. The injections were conducted on the day following the prelesion baseline recording.

(Fig. 1). The rats' behavior was video recorded simultaneously with EEG, EOG, and EMG data. The EEG and EMG signals were amplified, passed through high- and low-pass filters $(0.3 \mathrm{~Hz}$ and $10 \mathrm{kHz}$ cutoff for EEG; 1 $\mathrm{Hz}$ and $10 \mathrm{kHz}$ cutoff for EMG; Grass P511 or QP511 amplifier, GrassTelefactor, West Warwick, RI), and digitized at $256 \mathrm{~Hz}$. All signals were stored using SleepSign (Kissei Comtec, Irvine, CA) data acquisition software. Signals $>50 \mathrm{~Hz}$ were later filtered off-line using a low-pass digital filter in the software.

Lesions. On the day after the prelesion baseline recording, under anesthesia with the same mixture of anesthetics as above, 19 rats were injected bilaterally into the NBM/SI region with one of the following solutions: ACSF $(0.5 \mu \mathrm{l}$ per side; $n=5)$; IBO ( $8 \mu \mathrm{g}$ in $0.5 \mu \mathrm{l}$ of ACSF per side; Sigma-Aldrich, Oakville, Ontario, Canada; $n=8$ ); or 192IgG-saporin (192IgG-SAP; $0.26 \mu \mathrm{g}$ in $0.5 \mu \mathrm{l}$ of ACSF per side; Advanced Targeting Systems, San Diego, CA; lot numbers $41-105 ; n=6$ ). An additional group of 20 rats received unilateral injections of IBO $(8 \mu \mathrm{g}$ in $0.5 \mu \mathrm{l}$ of ACSF; IBO-UNI; $n=11)$ or ACSF $(0.5 \mu \mathrm{l}$; ACSF-UNI; $n=9)$. The IBO concentrations were chosen based on previous studies (Buzsaki et al., 1988; Cahill and Baxter, 2001; Pang et al., 2001) and a pilot study using a lower concentration of IBO $(0.8 \mu \mathrm{g}$ in $0.5 \mu \mathrm{l}$ of ACSF), which did not yield significant lesions. For 192IgG-SAP, a pilot study was conducted to determine an effective amount histologically, and this amount from the same batch of immunotoxin was used for the main study. Injections were made at a rate of $0.1 \mu \mathrm{l} / \mathrm{min}$ using an injector cannula (30G) inserted through the preimplanted guide cannula. The injector cannula was connected with plastic tubing to a $1 \mu \mathrm{l}$ Hamilton syringe. After injection, the injection cannula was left in place for $10 \mathrm{~min}$ and then withdrawn slowly. The animals were returned to their home cages and monitored until awake.

Postinjection recording. Using the same procedures as for the preinjection baseline recording, postinjection (postlesion for IBO and 192IgGSAP injections) recording sessions were performed for a $24 \mathrm{~h}$ period starting at 7:00 A.M. (lights on) on postinjection days 3, 7, 10, 17, 21, and 27 (Fig. 1).

Sleep deprivation and recovery sleep recording. After a $24 \mathrm{~h}$ recording on day 27 , which also served as the pre-SD baseline, polygraphic recording continued through $6 \mathrm{~h}$ of SD, which started at 12:00 P.M. SD was conducted by gentle handling either when animals assumed a sleep posture or when low-voltage fast-activity EEG was replaced by large-amplitude slow waves. The postdeprivation recording started at 6 P.M. and continued for the next $37 \mathrm{~h}$ (Fig. 1).

Perfusion. After completion of post-SD recording, rats were given an overdose of sodium pentobarbital (60 mg/kg, i.p.) and perfused transcardially with $50 \mathrm{ml}$ of saline followed by $400 \mathrm{ml}$ of $4 \%$ paraformaldehyde in PBS, pH 7.4. The brains were removed, postfixed in the same fixative for $2-4 \mathrm{~h}$, and stored in $30 \%$ sucrose in phosphate buffer at $4^{\circ} \mathrm{C}$ until histological processing. 
Sleep-wake state scoring and EEG data analysis

Digitized polygraphic data were analyzed off-line in $10 \mathrm{~s}$ bins using the SleepSign software followed by visual checking. The software was programmed to autoscore each epoch using an algorithm that identified six behavioral states based on standard criteria (Neckelmann and Ursin, 1993): active wake with movement (M), quiet wake (W), light NREM sleep (S1), deep NREM sleep (S2), transition to REM sleep (T), and REM sleep (R). Specifically, an epoch was marked M if the EMG integral was high $(>15 \mu \mathrm{V})$; S2 was marked when the EEG showed a high percentage of delta (1-4 Hz; $>50 \%$ of the epoch), whereas an epoch with predominant theta $(4.5-8 \mathrm{~Hz} ;>30 \%)$ with very low EMG $(<2 \mu \mathrm{V})$ was marked as $\mathrm{R}$; an epoch with a combination of delta $(<50 \%)$ and sigma $(8.5-13$ $\mathrm{Hz}$ ) waves was classified as $\mathrm{S} 1$, whereas an epoch with a combination of delta $(<50 \%)$ and theta $(<30 \%)$ was classified as T. To ensure that increase in delta power (based on previous studies using IBO injections in the BF; see Introduction) will not affect the state and waveform recognition, a very wide range was selected as the waveform amplitude (100$800 \mu \mathrm{V})$ for detection of delta wave. To compare the behavioral states and EEG across treatment groups, the six behavioral states were further grouped into three states: wake $(M+W)$, NREM sleep $(S 1+S 2)$, and REM sleep (T+REM). The autoscored data were then checked at least twice visually for movement and any other artifact to confirm or correct automatic state classification; concurrent video images of the animal's behavior aided in this process. The epochs with movement artifacts were excluded from subsequent EEG spectral analysis, which resulted in overall rejection of $37 \%$ of $\mathrm{W}$ epochs, and $11 \%$ of NREM and $7 \%$ of REM sleep epochs. The EEG data from both the hemispheres were then digitally low-pass filtered at $50 \mathrm{~Hz}$ and tapered (Hanning window), and spectral analyses were conducted using fast Fourier transform. The integrated power of EEG was analyzed in $2 \mathrm{~s}$ bins in the following frequency ranges: delta $(1-4 \mathrm{~Hz})$, theta $(4.5-8 \mathrm{~Hz})$, sigma $(8.5-13 \mathrm{~Hz})$, beta $(13.5-30 \mathrm{~Hz})$, and gamma $(30.5-50 \mathrm{~Hz})$.

The changes in times spent in wake, NREM sleep, and REM sleep on days $3,7,10,17,21$, and 27 after IBO, SAP, or ACSF injection were compared statistically, as described below, with respective preinjection baselines as well as between the three treatment groups. Similarly, the time course of changes in the EEG power values in wake, NREM sleep, and REM sleep after IBO, SAP, or ACSF injection was analyzed statistically, after the EEG power values were normalized as percentages of respective preinjection (baseline) values to control for individual and interlead differences in absolute power value. Specifically, the time course of these behavioral state and EEG changes over $27 \mathrm{~d}$ postinjection in three groups was examined using two-way ANOVA with repeated measures on days. When this ANOVA indicated a significant day or treatment effect or interaction, one-way ANOVA was conducted to compare between treatments or days, followed by Fisher's protected least significant difference (PLSD) test for pairwise multiple comparisons. The data for the light and the dark phase were analyzed separately. In the unilateral injection groups (IBO-UNI and ACSF-UNI), loss of headcaps over time after IBO or ACSF injections in a number of animals resulted in unbalanced subject numbers ( $n=8$ and 9 , respectively, at day $3 ; n=7$ for ACSF at day 10 ; and $n=6$ each group, at days 17,21 , and 27). Therefore, these data were analyzed first using two-way ANOVA, and after establishing significance, a nonparametric Mann-Whitney $U$ test was conducted at each time point for paired comparison. All statistical analyses were done using Statview 5.0 statistical software (SAS Institute, Cary, $\mathrm{NC}$ ). A probability of $<0.05$ was considered significant. Results are expressed with means \pm SEM.

\section{Histological processing and analyses}

Brains were cut into $40 \mu \mathrm{m}$ sections on a freezing microtome, and five sets of serial sections were collected. One series was processed for Nissl staining. Two series were immunohistochemically stained to visualize cholinergic and noncholinergic, parvalbumin (PARV)-containing BF neurons, using a goat polyclonal antibody to vesicular acetylcholine transporter (VAChT; AB1578, Millipore, Billerica, MA; 1:15,000) and a mouse monoclonal antibody to PARV (PARV-19) (Sigma; 1:1000), respectively, with a standard $\mathrm{ABC}$ method and diaminobenzidine as a chromogen as described previously (Deurveilher et al., 2006). The anti-
VAChT antibody was raised against a synthetic peptide representing amino acids 511-530 from cloned rat VAChT [technical information provided by the supplier; for its specificity, see Deurveilher et al. (2006)]. The monoclonal PARV antibody was raised against purified muscle parvalbumin, and its isotype was confirmed by double diffusion immunoassay (technical information provided by the supplier). A fourth series was stained for acetylcholinesterase (AChE) to assess the loss of cholinergic fibers in the cortex, using a sensitive histochemical protocol by Tago et al. (1986). A fifth series was stored as backup.

The sites of injections in the BF were determined using Nissl-stained sections based on the track of the injector cannula showing minor necrosis. The extents of IBO lesions were assessed based on loss of neurons and gliosis in Nissl-stained sections. The extents of the loss of VAChT- and PARV-immunoreactive neurons in the BF were assessed by plotting these neurons in a total of $14-16$ sections at $\sim 250 \mu \mathrm{m}$ intervals throughout the BF from the medial septum to the NBM using Neurolucida (MicroBrightField, Williston, VT) with a $10 \times$ objective lens, and counting them on the plots using Scion Image (version $\beta$ 4.0; Scion, Frederick, MD). The cell counts from two adjacent sections $250 \mu \mathrm{m}$ apart were averaged, and these cell counts at $500 \mu \mathrm{m}$ intervals over a total extent of $4.0 \mathrm{~mm}$ were compared statistically between the treatment groups. In a few instances in which one of the two sections was judged unsuitable for cell counting for technical reasons, the count from only one section was used.

Cortical AChE staining density was quantified in each animal first by capturing an image $\left(1 \times 1 \mathrm{~mm}^{2}\right)$ of the lateral parietal cortex at $\sim 500$ $\mu \mathrm{m}$ intervals ( $1.5 \mathrm{~mm}$ anterior to $4.0 \mathrm{~mm}$ posterior to bregma; the medial segment of the image positioned at $4 \mathrm{~mm}$ lateral to midline), including the somatosensory cortex, using a $10 \times$ objective lens. An analysis box $(0.25 \mathrm{~mm}$ wide $\times 1.05 \mathrm{~mm}$ high $)$ was placed perpendicular to the cortical surface. Integrated density of the area within the analysis box was then measured (see Fig. 5A). Integrated density refers to the total gray value of all pixels (within each analysis box) below (i.e., darker than) a threshold systematically set by an investigator (M.A.B.) blind to the treatment conditions (Scion Image, $\beta$ 4.0).

The VAChT-IR and PARV-IR BF cell counts and the integrated AChE density values from the cortex of the IBO and SAP groups were normalized as the percentage of the respective mean cell count or integrated density value of the control (ACSF) group at each corresponding anatomical level. The normalized cell counts and integrated densities were compared using two-way ANOVA with repeated measures on anatomical levels. When ANOVA indicated significant effects of the treatment or anatomical levels, or significant interaction between the main effects, a one-way ANOVA followed by Fisher's PLSD tests was conducted for pairwise multiple comparisons. The VAChT cell count of one animal was eliminated from statistical analysis because of technical problems with immunostaining.

\section{Results}

\section{Histological analyses of IBO and 192IgG-SAP lesions}

Figure 2 shows the sites of ACSF $(B)(n=5)$ and 192IgG-SAP injections $(D)(n=6)$, and the extents of IBO lesions $(C)(n=6)$, based on Nissl staining for all bilateral injection cases. All the injection sites were centered at the NBM and SI regions, mostly at $1.3-1.8 \mathrm{~mm}$ posterior to bregma. IBO lesions, as determined by loss of neurons and gliosis, were mostly confined to the NBM/SI regions, with slight involvement of adjacent regions, including the bed nucleus of the stria terminalis and thalamic or hypothalamic regions (Fig. 2C).

The loss of PARV + and VAChT + BF neurons after IBO and SAP injections was analyzed quantitatively for all bilateral injection cases $(n=17)$, as described below. The results of unilateral injections $(n=17)$ (data not shown) were very similar to those of bilateral injections in terms of injection sites and the degrees of cell loss on the affected side. It has previously been reported that intraparenchymal injections of 192IgG-SAP did not destroy noncholinergic BF neurons containing neurotensin, galanin, somatostatin, NADPH-diaphorase, or neuropeptide Y (Wenk et al., 
1994), nor did they affect cortical monoamine levels (Pizzo et al., 1999).

\section{PARV- and VAChT-immunoreactive neurons in the $\mathrm{BF}$}

Figure 3 shows representative microscopic images of the NBM/SI region depicting abundant PARV-positive $(+)$ and VAChT + neurons after ACSF injection $(A, B)$; a marked loss of PARV + neurons and a moderate loss of VAChT + neurons after IBO injection $(C, D)$; and no apparent loss of PARV + neurons but a nearly complete loss of VAChT + neurons after SAP injection $(E, F)$.

To assess the rostrocaudal extent of cell loss quantitatively, PARV + and VAChT + cell counts of IBO and SAP groups were normalized as percentages of the respective cell counts of the ACSF group at 500 $\mu \mathrm{m}$ intervals throughout the BF (A1.2P2.8 mm) (Fig. 4). SAP injections had no significant effect on the number of PARV + cells relative to the ACSF group at any rostrocaudal level (Fig. $4 A$ ). IBO injections caused a significant loss of PARV + cells, by up to $67.3 \pm 3.6 \%$, particularly at caudal levels (two-way ANOVA with repeated measures on levels, treatment effect $F_{(2,31)}=11.45, p=$ 0.0002 ; treatment $\times$ level, $F_{(2,16)}=3.86$, $p<0.001)$. This reduction was significant compared with the ACSF group at all levels caudal to P0.3 $\mathrm{mm}$, and compared with the SAP group, at all levels caudal to $\mathrm{P} 1.3 \mathrm{~mm}$ $(p=0.0001-0.03$, Fisher's PLSD).

As expected, SAP injections resulted in an extensive loss of VAChT + neurons relative to the ACSF group, by up to $76.6 \pm$ $4.0 \%$ at $\mathrm{P} 1.8 \mathrm{~mm}$ (Fig. $4 C$ ). The reduction compared with ACSF and IBO groups was significant at all levels and most pronounced at P1.3-2.3 $\mathrm{mm}$ (treatment effect, $F_{(2,29)}=29.70, p<0.001$; treatment $\times$ level, $F_{(2,16)}=2.89$, $p=0.004$; Fisher's PLSD, $p=0.0001-0.036$ ). The loss of $\mathrm{VAChT}+$ neurons after IBO injections was relatively minor, and was significant only at $\mathrm{P} 0.3 \mathrm{~mm}$ with a $23.7 \pm 6.7 \%$ decrease compared with the ACSF group (Fisher's PLSD, $p=0.025$ ) (Fig. $4 C)$.

Because the normal number of PARV + or VAChT + neurons varied along the rostrocaudal extent of the $\mathrm{BF}$, the percentage loss at each level does not contribute equally to the percentage loss for the entire BF cell population. Therefore, cell counts were combined into the caudal BF (caudal to P0.3 mm), which contained the injection sites, and rostral BF (A1.2 to P0.3), which did not. These values were then normalized to respective ACSF cell counts (Fig. $4 B, D$ ). Thus, IBO injections resulted in a significant $42.7 \pm$ $3.1 \%$ decrease in PARV + cell counts in the caudal BF (one-way ANOVA, $F_{(2,31)}=15.13, p<0.001$; Fisher's PLSD, IBO $<$ SAP, $p=0.0003$; IBO $<$ ACSF, $p<0.001)$, and a less pronounced but significant $22.6 \pm 4.5 \%$ decrease in the rostral BF $\left(F_{(2,31)}=3.44\right.$, $p=0.044$; IBO $<$ ACSF, $p=0.015)$, but only nonsignificant decreases in VAChT + cell counts in both the rostral (11.6 \pm nucleus; VP, ventral pallidum.
B

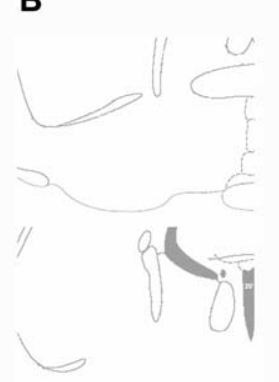

C

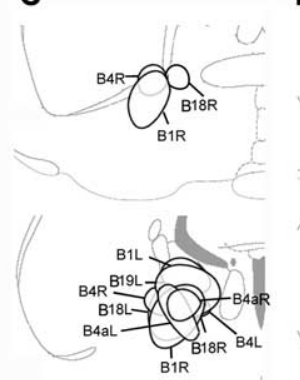

D
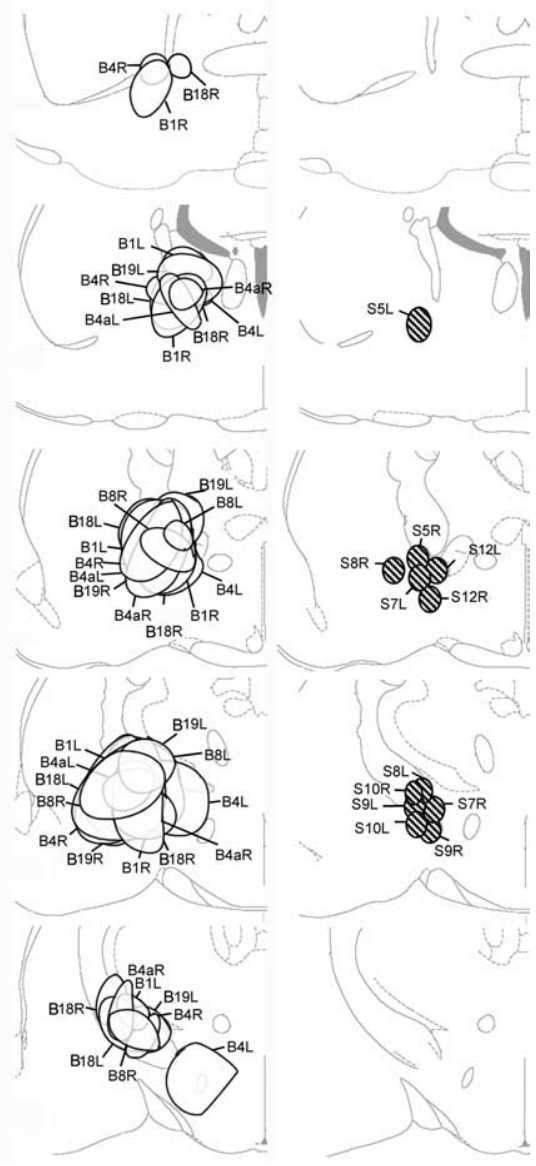

Figure 2. Location of injection sites. $\boldsymbol{A}$, The subnuclei of the basal forebrain complex containing magnocellular cholinergic projection neurons at five levels (numbers at the lower left corner indicate distances in millimeters posterior to bregma). $\boldsymbol{B}$, Sites finjection of artificial CSF $(n=5)$ determined from Nissl-stained sections. C, Extent of lesions after IBO injections $(n=6)$ based

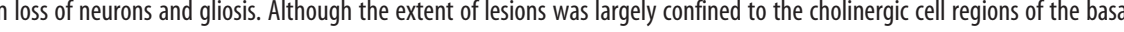
$\mathrm{mm}$ posterior to bregma. D. Approximate injection sites with 192/gG-SAP $(n=6)$ indicated by standardized hatched areas; the numbers of individual animals, with letters $L$ and $R$ indicating the side of injection or lesion. ac, Anterior commissure; HDB, horizontal limb of the diagonal band of Broca; f, fornix; ox, optic chiasm; MPA, magnocellular preoptic area; Rt, reticular thalamic

$1.9 \%)$ and caudal $(21.3 \pm 12.3 \%)$ BF. In contrast, SAP injections had no significant effect on PARV + cell counts regardless of BF level (10.9\% decrease in the caudal BF) (Fig. $4 B$ ), but significantly decreased VAChT + cells, by $68.8 \pm 3.8 \%$ in the caudal BF $\left(F_{(2,29)}\right.$ $=13.68, p<0.001$; SAP $<$ IBO, $p=0.0007$ and SAP $<$ ACSF, $p<0.001)$, and by $44.2 \pm 2.4 \%$ in the rostral BF $\left(F_{(2,29)}=31.10\right.$, $p<0.001$; SAP $<$ IBO, ACSF, $p<0.001$ ) (Fig. $4 D$ ).

\section{AChE staining in the neocortex}

SAP injections depleted AChE staining extensively throughout the neocortex, particularly in lateral regions corresponding to the somatosensory cortex, whereas IBO injections resulted in a less depletion in the same regions (Fig. 5A). Quantitatively, SAP injections reduced AChE staining density by $83.8 \pm 0.8 \%$ in the lateral cortex from A1.5 to P4 mm, whereas IBO injections caused a substantially less $40.5 \pm 7.8 \%$ depletion in the same regions (Fig. $5 B, C$ ). The AChE densities in both SAP and IBO groups were significantly lower than in the ACSF group at all rostrocaudal levels (two-way ANOVA with repeated measures on levels, 

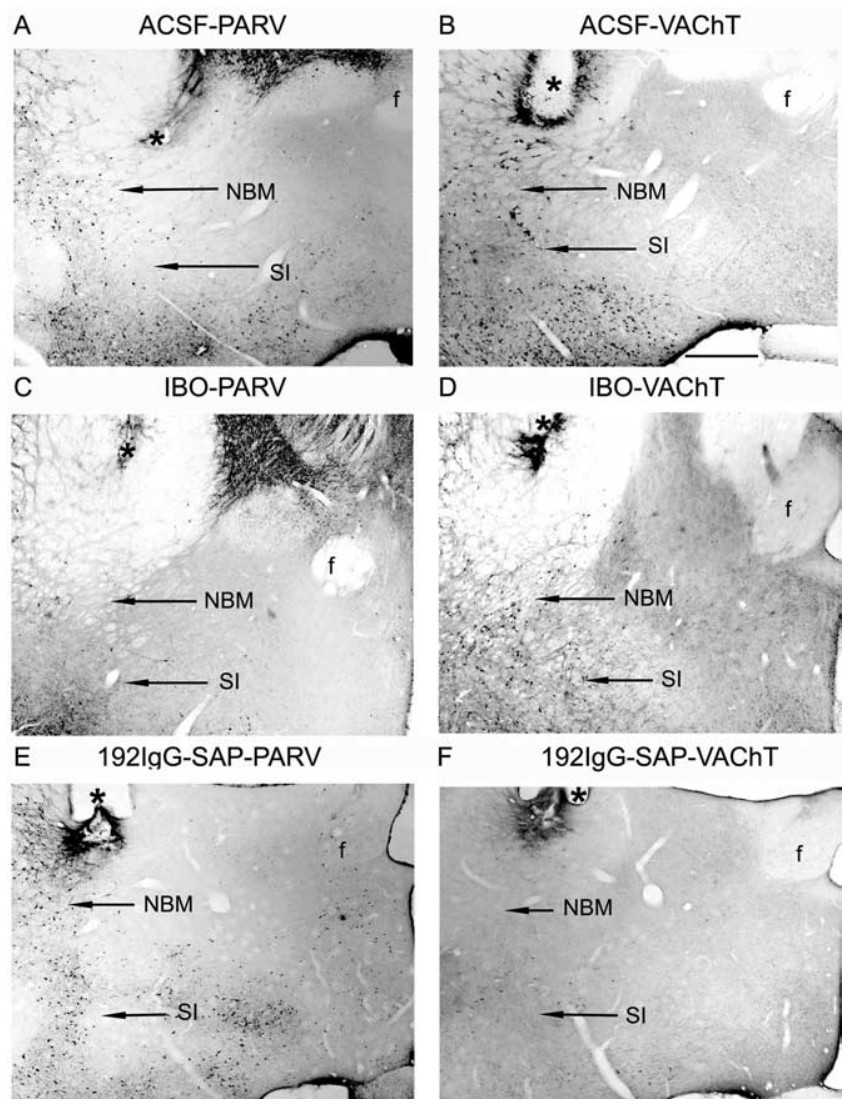

Figure 3. Representative micrographic images of coronal sections showing the PARVimmunoreactive $(\boldsymbol{A}, \boldsymbol{C}, \boldsymbol{E})$ and VAChT-immunoreactive neurons $(\boldsymbol{B}, \boldsymbol{D}, \boldsymbol{F})$ in the NBM/SI from animals injected with $\operatorname{ACSF}(\boldsymbol{A}, \boldsymbol{B}), \mathrm{IBO}(\boldsymbol{C}, \boldsymbol{D})$, or $192 \mathrm{lgG}-\mathrm{SAP}(\boldsymbol{E}, \boldsymbol{F})$ into the NBM/SI. $\boldsymbol{A}$ and $\boldsymbol{B}, \boldsymbol{C}$ and $\boldsymbol{D}$, and $\boldsymbol{E}$ and $\boldsymbol{F}$ for each treatment group are respectively from the same animals. Asterisks indicate the damage caused by guide and/or injector cannula. f, Fornix. Scale bar, $500 \mu \mathrm{m}$.

treatment effect, $F_{(2,31)}=31.43, p<0.001$; Fisher's PLSD, $p=$ 0.001-0.023) (Fig. 5B).

\section{Effects on baseline sleep-wake states}

Bilateral IBO lesions of the NBM/SI had no effects on the percentages of time spent in wake, NREM sleep, and REM sleep during either the light or the dark phase, when compared with the prelesion levels or the ACSF group at any time point after the lesion (Table 1). Unilateral IBO lesions also had no effect on the percentages of time spent in these behavioral states at any time point compared with their prelesion baselines or with unilateral ACSF controls (data not shown).

Unlike IBO lesions, bilateral SAP lesions had transient effect on behavioral states, and these effects were more pronounced during the dark than during the light phase (Table 1). Specifically, animals with SAP lesions overall showed significantly higher percentage of time spent in NREM sleep during the dark phase, compared with the ACSF and IBO groups (two-way ANOVA with repeated measures on days, day $X$ treatment interaction, $\left.F_{(2,10)}=2.24, p=0.025\right)$, and this increase was significant on day 3 (one-way ANOVA between treatment groups, $F_{(2,14)}=3.96$, $p=0.043$; Fisher's PLSD, SAP $>$ ACSF, $p=0.014), 7\left(F_{(2,14)}=\right.$ $4.26, p=0.036$; SAP $>$ ACSF, $p=0.024)$, and $10\left(F_{(2,14)}=4.43\right.$, $p=0.032$; SAP $>$ ACSF, $p=0.027)$ after the lesion compared with the ACSF control, and on day 7 ( $F$ as above; $\mathrm{SAP}>\mathrm{IBO}, p=$ $0.026)$ and 10 ( $F$ as above: $\mathrm{SAP}>\mathrm{IBO}, p=0.019)$ compared with the IBO group. These transient increases in NREM sleep up to day 10 postlesion represented an average of $13.2 \%$ increase from the preinjection baseline. This increase in NREM sleep was at the expense of wake time (two-way ANOVA with repeated measures on days; day $\times$ treatment interaction, $F_{(2,10)}=2.05, p=0.04$ ), which was significantly decreased on day 3 postlesion compared with the ACSF group $\left(F_{(2,14)}=3.16, p=0.04\right.$; Fisher's PLSD, $p=$ $0.025)$, and on day 10 compared with the IBO group $\left(F_{(2,14)}=\right.$ $2.95, p=0.05$; Fisher's PLSD, $p=0.045)$. The amount of NREM sleep returned to ACSF control levels by day 17. The percentage of time spent in REM sleep was not significantly affected in any treatment group or for any day of recording.

During the light phase, NREM sleep amounts after SAP lesions were similar to those after ACSF or IBO injections, with the exception of a significant increase seen on day 7 postlesion (twoway ANOVA with repeated measures on days; day $\times$ treatment, $F_{(2,10)}=3.07, p=0.0027$; one-way ANOVA between treatment groups on day $7, F_{(2,14)}=4.63, p=0.028$; Fisher's PLSD, SAP $>$ ACSF, $p=0.009)$.

\section{Effects on the baseline EEG}

Power values in five frequency ranges were calculated for the EEG from each hemisphere during light and dark phases up to $27 \mathrm{~d}$ after bilateral injection of IBO $(n=6)$, SAP $(n=6)$, or ACSF $(n=5)$ into the NBM/SI. The values after injections are expressed as percentages of respective preinjection baseline values for each hemisphere.

\section{Bilateral IBO and SAP lesions}

The main effects of bilateral IBO and SAP lesions on EEG power values were that IBO lesions increased delta power during all three behavioral states, and most dramatically during NREM sleep, whereas SAP lesions had no effects on the EEG during any behavioral state.

For NREM sleep, postinjection NREM sleep delta power values relative to prelesion baselines were significantly different among the three treatment groups from days 3 to 27 postlesion for both light (two-way ANOVA with repeated measures on days, treatment effect, $\left.F_{(2,31)}=7.39, p=0.0024\right)$ and dark phases (treatment effect, $\left.F_{(2,31)}=7.19, p=0.0027\right)$. For the light phase, the percentage increase in delta power in the IBO group rose from $19.2 \%$ on day 3 postlesion to $61.8 \%$ on day 10 and remained high through day 27 (Fig. 6, middle, black circles). A paired comparison at each postlesion day revealed that NREM sleep delta values in the IBO group were significantly higher than in the ACSF or SAP group consistently from day 3 to day 27 (IBO $>$ SAP, ACSF, $p=0.001-0.034)$. NREM delta power during the dark phase also increased after IBO lesions (Fig. 7), similar to during the light phase, from day $3(8.9 \%)$ to day $21(38.7 \%)$ and to day 27 $(48.3 \%)$. The increase in NREM sleep delta was significant on all postinjection recording days except for day 10 and 17 (IBO > SAP, ACSF, $p=0.005-0.0002$, for days 3, 7, 21, and 27) (Fig. 7).

Although not as pronounced as during NREM sleep, IBO lesions also increased delta power during REM sleep and, to a lesser extent, during wake in the light phase (Fig. 6, bottom and top); similar trends were seen in the dark phase (Fig. 7). The increase in delta power during REM sleep was significant during the light phase (two-way ANOVA with repeated measures on days, treatment effect, $\left.F_{(2,31)}=3.38, p=0.047\right)$ and specifically on days 3 $(\mathrm{IBO}>\mathrm{ACSF}$, SAP, $p=0.049,0.005), 7(\mathrm{IBO}>\mathrm{SAP}, p=0.04)$, 21 (IBO > ACSF, SAP, $p=0.029,0.021$ ), and 27 (IBO > ACSF, $\mathrm{SAP}, p=0.05,0.027)$. During wake, the IBO group showed nonsignificant trends of an increase in delta power during both light and dark phases (Figs. 6, 7). 
In addition to delta power, IBO lesions resulted in a transient increase in theta power during NREM sleep (Figs. 6, 7, red circles), with a peak around day 7-10 postlesion. Relative theta power during NREM sleep was significantly different between the treatment groups during both light (two-way ANOVA with repeated measures on days, treatment effect, $F_{(2,31)}$ $=4.91 ; p=0.014$ ) and dark phases (treatment effect, $\left.F_{(2,31)}=5.97, p=0.0064\right)$, with the IBO group showing a significant increase in theta compared with the ACSF and SAP groups on day 7 (light phase: $F_{(2,31)}=8.04, p=0.0015$; dark phase: $F_{(2,31)}=10.03, p=0.004$ ) and 10 (light phase: $F_{(2,31)}=5.34, p<0.012$; IBO $>$ SAP, $p=0.02$; dark phase: $F_{(2,31)}=4.47$, $p=0.019$; IBO $>$ ACSF, SAP, $p=0.04$, $0.007)$.

With the exception of the changes in delta and theta power values in the IBO group as noted above, EEG power values in all frequency bands tended to decrease in all treatment groups after injections relative to preinjection baselines. The reason for these general decreases is unclear.

\section{Correlations between baseline EEG delta power and loss of}

PARV/VAChT-immunoreactive neurons

To assess whether the increase in baseline delta power was correlated with the loss of PARV neurons, Pearson's correlation coefficients were calculated, for each behavioral state, between the percentage loss of $\mathrm{PARV}+$ cells in the caudal BF relative to the ACSF control (Fig. $4 \mathrm{~B}$, right), and the amount of delta power relative to prelesion/injection baselines (Figs. 6,7$)$ in the combined bilateral IBO $(n=6)$, SAP $(n=$ $6)$, and $\operatorname{ACSF}(n=5)$ groups at days 3,7 ,

$10,17,21$, and 27 postinjection for both the light and dark phases. For NREM sleep, loss of PARV + cells in the caudal BF was positively correlated with the delta power in both the light and dark phases at all time points after lesion (light phase: $r=0.68-0.78$, $p<0.01-0.001$; dark phase: $r=0.49-0.74, p<0.05-0.01)$. For wake and REM sleep, there were trends for a positive correlation between percentage of PARV cell loss and delta power, which reached statistical significance at day 3 postlesion for wake $(r=$ $0.50, p<0.05)$, and day 21 and 27 for REM sleep ( $r=0.53$ and $0.52 ; p<0.05)$. Unlike PARV neurons, there was no significant correlation between loss of VAChT + neurons and the amount of delta power in any behavioral state and at any time point after injections.

\section{Unilateral IBO lesions}

The BF projections to the cortex are known to be exclusively unilateral (Semba and Fibiger, 1989). Therefore, the effects of unilateral (left) IBO injections into the NBM/SI (IBO-UNI, $n=$ 8) were compared with those of unilateral ACSF injections (ACSF-UNI, $n=9$ ) on the EEG recorded from the cortices ipsilateral and contralateral to injection. Unexpectedly, IBO-UNI
B

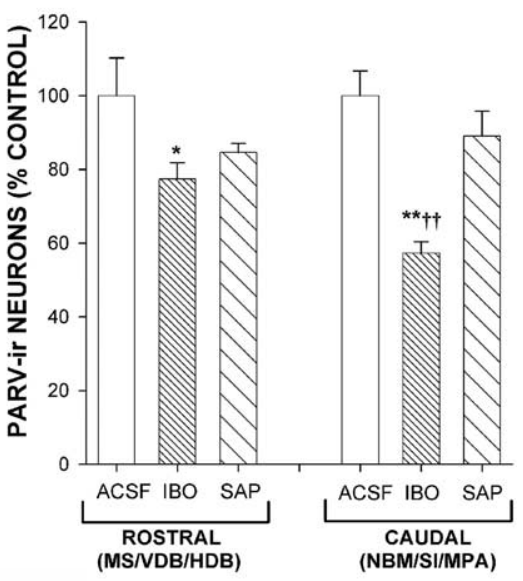

D

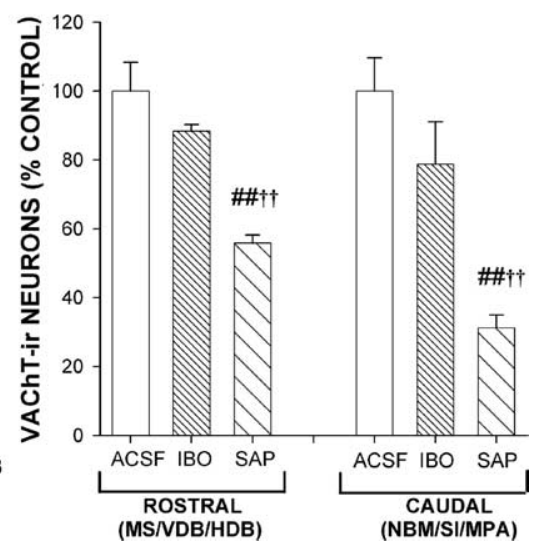

Figure 4. Loss of PARV-IR and VAChT-IRBF neurons in animals injected with IBO and 192IgG-SAP compared with those injected with ACSF (control). $A, C$, The percentage (mean \pm SEM) of PARV-IR $(\boldsymbol{A})$ and VAChT-IR $(\boldsymbol{C})$ cells in IBO and SAP-injected animals relative to ACSF controls along the rostrocaudal axis of the basal forebrain at $500 \mu \mathrm{m}$ intervals. The number of PARV-IR and horizontal (HDB) limbs of the diagonal band of Broca] and the caudal BF [NBM, SI, and magnocellular preoptic area (MPA)] after IB0 and 192lgG-SAP lesions normalized to ACSF levels. A-D, IBO $<$ ACSF, ${ }^{*} p<0.05,{ }^{* *} p<0.01 ;$ SAP $<$ ACSF, ${ }^{\#} p<0.05,{ }^{\# \#} p<$ $0.01 ; \mathrm{SAP}<\mathrm{IBO},{ }^{\dagger} p<0.05,{ }^{\dagger \dagger} p<0.01$ (see Results for ANOVA).

lesions resulted in an increase in EEG delta power both ipsilateral and contralateral to the lesion, particularly during NREM sleep, although the magnitude of the increases was generally smaller than after bilateral lesions and the increase on the contralateral side returned to prelesion levels by 3 weeks postlesion.

Specifically, during the light phase, IBO-UNI lesions caused a significant increase in ipsilateral NREM delta relative to prelesion baselines consistently up to day 27 postlesion (two-way ANOVA with repeated measures on days, treatment effect, $F_{(1,8)}=37.74$, $p=0.0003$; IBO $>$ ACSF, followed by Mann-Whitney $U$ test for pairwise comparison at each time point, $p=0.00078-0.044$ ). The magnitude of the increase, however, tended to diminish gradually after 1 week postlesion (Fig. $8 \mathrm{~A}$ ), in contrast to the effects of bilateral IBO lesions that remained high or tended to intensify over time. Similar increases in delta power were observed during the dark phase (treatment effect, $F_{(1,8)}=25.18, p=$ $0.0011)$, but these were significant only on day $3(p=0.020$, Mann-Whitney $U$ test $), 7(p=0.027), 10(p=0.028)$, and 27 $(p=0.017)$ postlesion (Fig. $8 B)$.

The EEG recorded from the cortex contralateral to the NBM/SI lesions also showed increased delta power during 
A ACSF

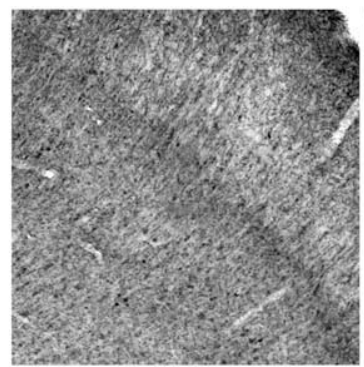

B

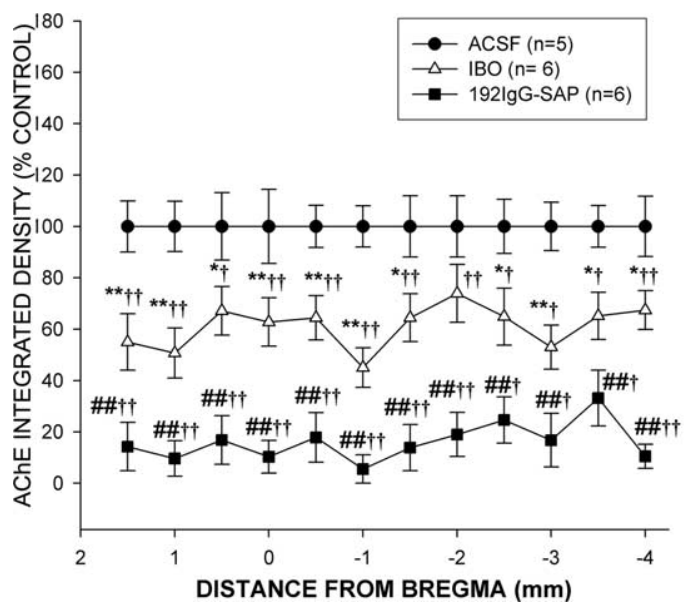

IBO

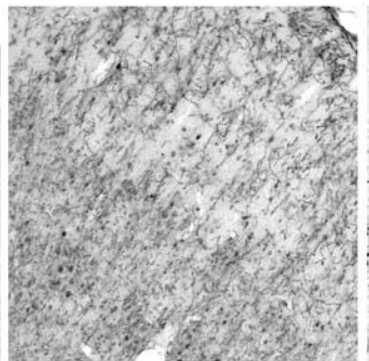

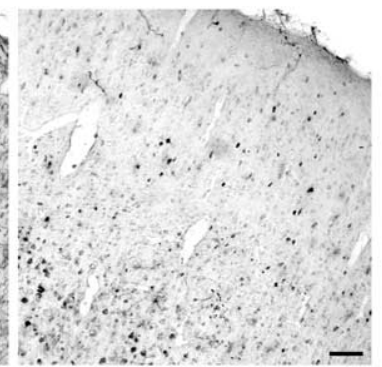

C

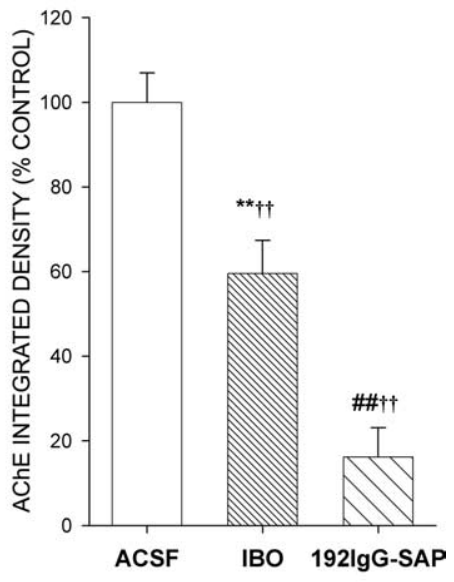

Figure 5. Cholinergic fiber loss after IBO and 192lgG-SAP microinjections into the NBM/SI. $A$, Representative photomicrographs of AChE-stained sections showing the lateral (somatosensory) cortex from animals injected with ACSF, IBO, or SAP. Note marked depletion of AChE staining after SAP, and moderate depletion after IBO, compared with the ACSF control. Scale bar, 100 $\mu \mathrm{m} . \boldsymbol{B}, \boldsymbol{C}$, Integrated density of AChE staining (mean \pm SEM) in IBO, SAP, and ACSF groups normalized to the ACSF (control) group at different rostrocaudal levels $(\boldsymbol{B})$ and across all levels $(\boldsymbol{C})$ of the somatosensory cortex from $2 \mathrm{~mm}$ anterior to $4 \mathrm{~mm}$ posterior to bregma. $B, C$, IBO $<$ ACSF, ${ }^{*} p<0.05,{ }^{* *} p<0.01 ; 192 \mathrm{lgG}-\mathrm{SAP}<\mathrm{ACSF},{ }^{\#} p<0.05,{ }^{\# \#} p<0.01 ; 192 \mathrm{lgG}-\mathrm{SAP}<\mathrm{IBO},{ }^{\dagger} p<0.05$, ${ }^{+\dagger} p<0.01$ (1-way ANOVA followed by Fisher's PLSD, after significant treatment effect in 2-way ANOVA).
192lgG-SAP

Effects on recovery sleep and EEG after sleep deprivation

At the completion of spontaneous sleepwake recordings on day 27 postlesion, the animals were challenged with $6 \mathrm{~h}$ of SD during the light phase [Zeitgeber time (ZT) 5-11] to examine the effects of lesions on recovery sleep and EEG. Six hours of SD has been shown reliably to increase NREM sleep and EEG slow-wave activity (Tobler and Borbely, 1990). Scheduling $6 \mathrm{~h}$ of SD during the latter part of the light phase allows recovery sleep to occur during the early dark phase when rats normally exhibit increased activity (Lancel and Kerkhof, 1989).

This section mainly describes the effects of bilateral lesions with IBO and 192IgG-SAP. Unilateral lesions with IBO had no effects on rebound sleep and only minor effects on recovery EEG delta power, as summarized at the end of this section.

Figure 9 shows representative polygraphic recordings and hypnograms of animals from the three treatment groups, including EEG power values in delta range, during the $29 \mathrm{~h}$ pre-SD, $6 \mathrm{~h}$ of SD, and $37 \mathrm{~h}$ postdeprivation periods. The hypnograms from animals with bilateral IBO and SAP lesions (bottom two panels) depict smaller amounts of recovery NREM sleep ( $\mathrm{S} 1$ and S2), particularly during the first $12 \mathrm{~h}$ after $\mathrm{SD}$, compared with an ACSF-injected animal (top). A quantitative analysis of recovery sleep is described below.

\section{Effects on wake-theta power during sleep deprivation}

NREM sleep in both light (two-way ANOVA, treatment effect, $F_{(1,8)}=15.96 ; p=0.004$ ) and dark phases (two-way ANOVA, treatment effect, $F_{(1,8)}=19.41, p=0.0023$ ) with a time course similar to the increases seen on the ipsilateral EEG (Fig. 8C,D). This increase was significant for days 3 ( $p=0.027$, Mann-Whitney $U$ test $)$ and $10(p=0.0045)$ postlesion during the light phase (Fig. $8 C)$, and days $3(p=0.0038), 7(p=0.020)$, and $17(p=$ 0.032 ) during the dark phase (Fig. $8 D$ ).

Increased delta power was also observed during wake after IBO-UNI lesions, although this increase was significant only on day 3 ( $p=0.049$, Mann-Whitney $U$ test) and during the light phase (data not shown). IBO-UNI lesions did not affect the EEG power values in other frequency bands regardless of laterality, behavioral state, or phase.

Similar changes in EEG delta power on the unlesioned hemisphere have been observed previously (Holschneider et al., 1997) with greater asymmetries in lower frequencies during the active behaviors than during sleep (Kleiner and Bringmann, 1996). Because BF projections to the cortex are virtually exclusively unilateral (Semba and Fibiger, 1989), delta waves during NREM sleep might propagate to the contralateral hemisphere (Massimini et al., 2004) through transcallosal pathways (Vyazovskiy et al., 2004). A possible role of inter-BF commissural connections (Wenk et al., 1980; Semba et al., 1988) in these contralateral EEG changes cannot be excluded.
A progressive increase in theta power during wake as a result of SD has been proposed as a measure of sleep propensity (Borbely and Achermann, 2005; Vyazovskiy and Tobler, 2005). We therefore analyzed the time course of changes in theta power value over $6 \mathrm{~h}$ of SD. In the ACSF group, the theta power value during wake increased gradually over the first $2 \mathrm{~h}$ of $\mathrm{SD}$, reaching a plateau by the fourth hour (Fig. 10 A). In contrast, both IBO and SAP groups showed relatively small variation in theta power throughout the $6 \mathrm{~h}$ period, although the IBO group tended to show generally higher theta values than the SAP or ACSF group (two-way ANOVA with repeated measures on time, time $\times$ treatment effect, $F_{(2,10)}=2.85, p=0.0027$ ) (Fig. $10 A$ ). As an index of this trend, we used a ratio of the mean theta value during the last $4 \mathrm{~h}$ of SD to that during the first $2 \mathrm{~h}$. As shown in Figure $10 \mathrm{~B}$, this ratio was significantly lower in the SAP group $(3.45 \pm 1.06)$ and the IBO group $(0.78 \pm 1.02)$ than in the ACSF group (8.66 \pm 3.06; one-way ANOVA, $F_{(2,31)}=5.32, p=0.01$; IBO $<$ ACSF, $p=0.0029 ; \mathrm{SAP}<\mathrm{ACSF}, p=0.04)$. These results indicate that both IBO and 192IgG-SAP lesion groups failed to show an increase in theta power during $6 \mathrm{~h}$ of SD, suggesting that both lesions compromised the animal's ability to accumulate sleep propensity during enforced wake state. 
Table 1. Percentages of time spent in wake, NREM sleep, and REM sleep before and after bilateral injections of ACSF, IB0, or 192lgG-SAP into the nucleus basalis magnocellularis/substantia innominata

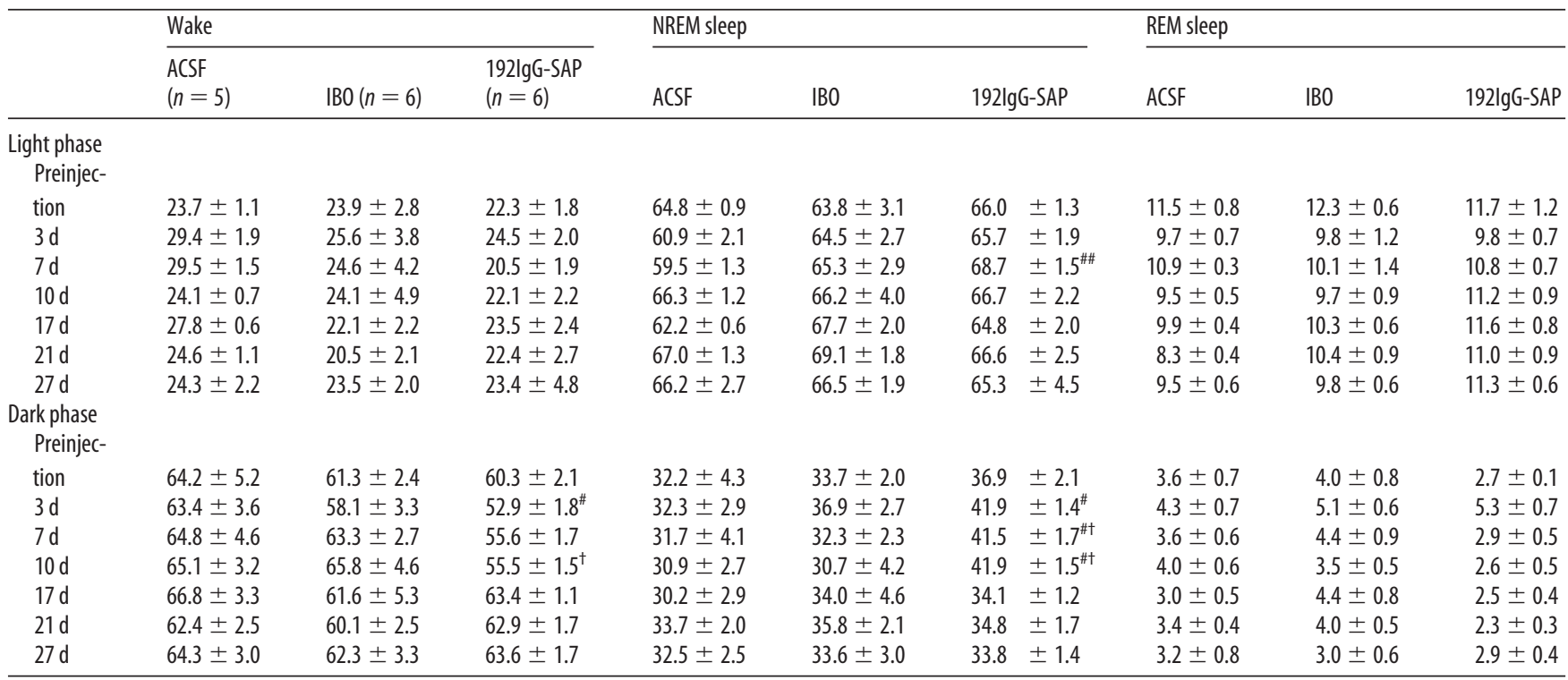

${ }^{\#}$ ACSF versus SAP, $p<0.05$; ${ }^{* \# A}$ ACSF versus SAP, $p<0.01 ;{ }^{\dagger} \mid \mathrm{B} 0$ versus SAP, $p<0.05$ (one-way ANOVA followed by Fisher's PLSD, after significance in two-way ANOVA for treatment $\times$ time interaction).
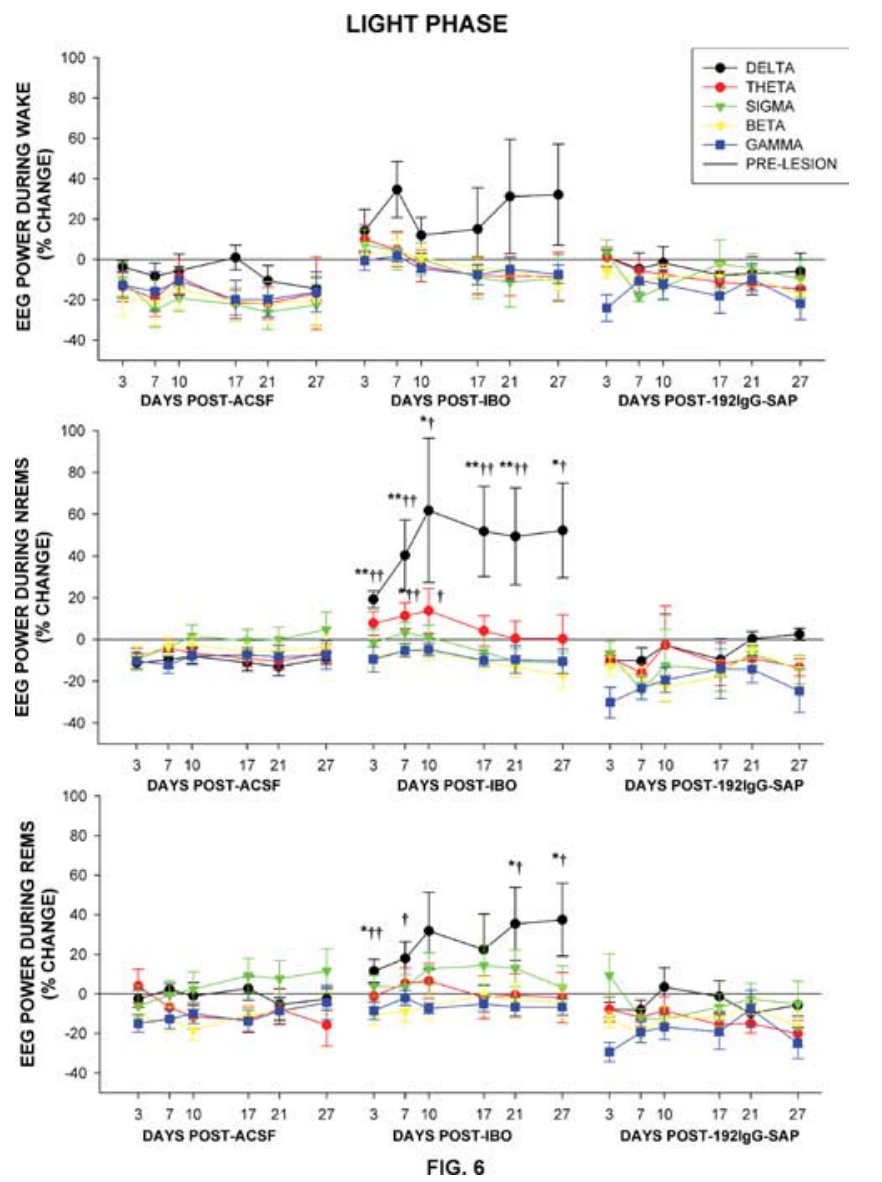

Figure 6. Time courses of changes in the EEG power in five frequency ranges in wake, NREM sleep, and REM sleep during the light phase after bilateral ACSF, IBO, or 192lgG-SAP injections into the NBM/SI over a $27 \mathrm{~d}$ period after injection. EEG power values are expressed as percentages (mean $\pm \mathrm{SEM}$ ) of the difference from their respective preinjection baselines. EEG frequency ranges: delta, $1-4 \mathrm{~Hz}$; theta, $4.5-8 \mathrm{~Hz}$; sigma, $8.5-13 \mathrm{~Hz}$; beta, $13.5-30 \mathrm{~Hz}$; gamma, $30.5-60 \mathrm{~Hz}$. IBO $>$ ACSF, ${ }^{*} p<0.05,{ }^{* *} p<0.01 ; \mathrm{IBO}>192 \mathrm{lgG}-\mathrm{SAP},{ }^{\dagger} p<0.05,{ }^{\mathrm{t \dagger}} p<0.01$ (1-way ANOVA followed by Fisher's PLSD, after the significance was established in 2-way ANOVA for treatment $\times$ time).
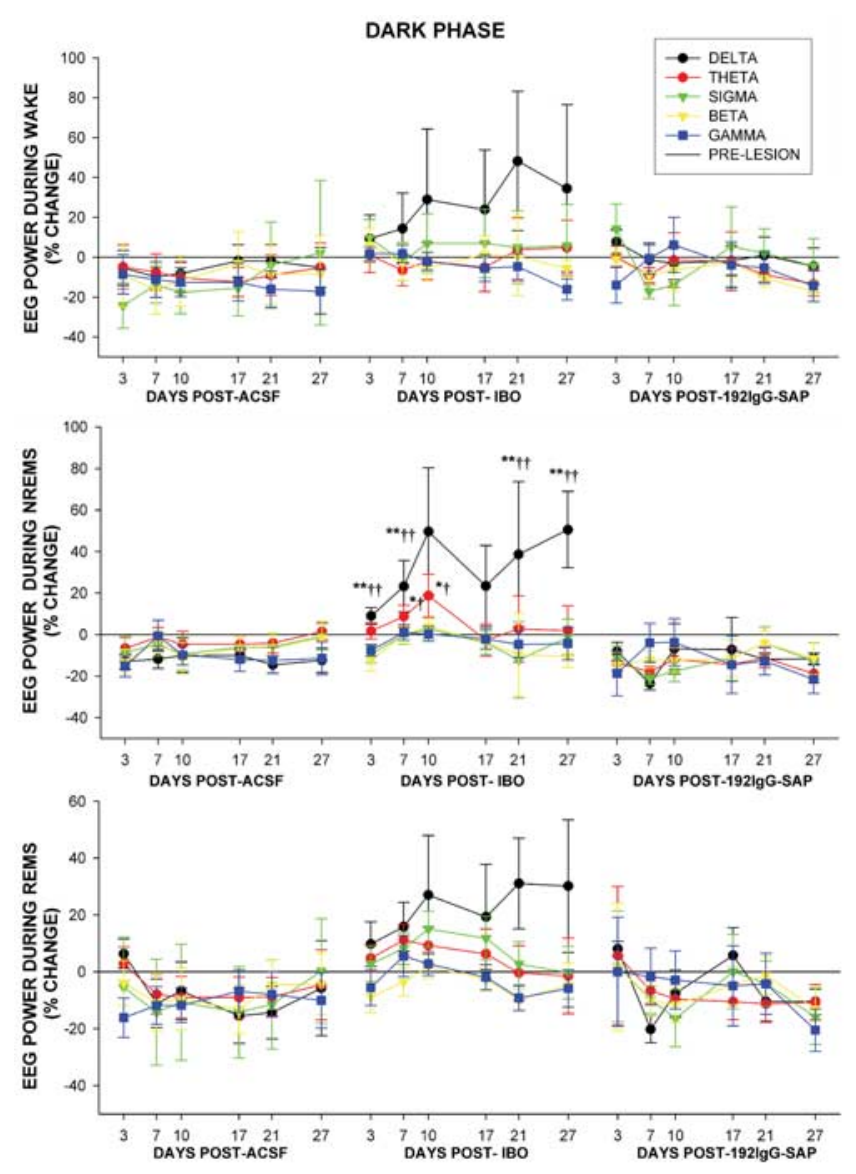

Figure 7. Time course of changes in the EEG power in wake, NREM sleep, and REM sleep during the dark phase after bilateral ACSF, IB0, or 192lgG-SAP injections into the NBM/SI over a $27 \mathrm{~d}$ postinjection period. EEG powers are expressed as percentages (means \pm SEM) of preinjection baselines. IBO $>$ ACSF, ${ }^{*} p<0.05,{ }^{* *} p<0.01$; IBO $>192 \mathrm{lgG}-\mathrm{SAP},{ }^{+} p<0.05,{ }^{{ }^{+\dagger}} p<$ 0.01 (1-way ANOVA followed by Fisher's PLSD, after the significance was established in 2-way ANOVA for treatment $\times$ time) 


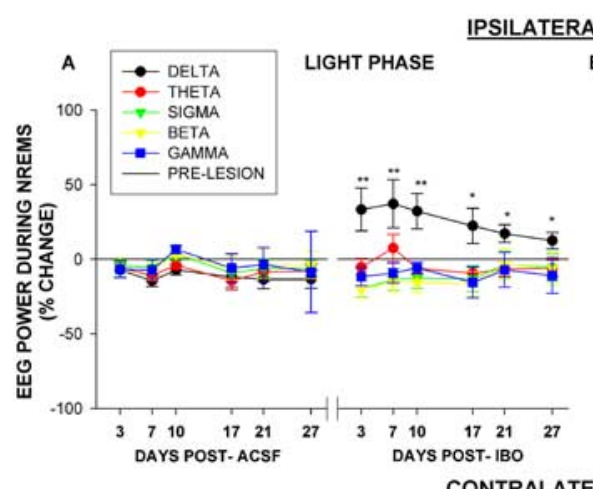

AL TO LESION
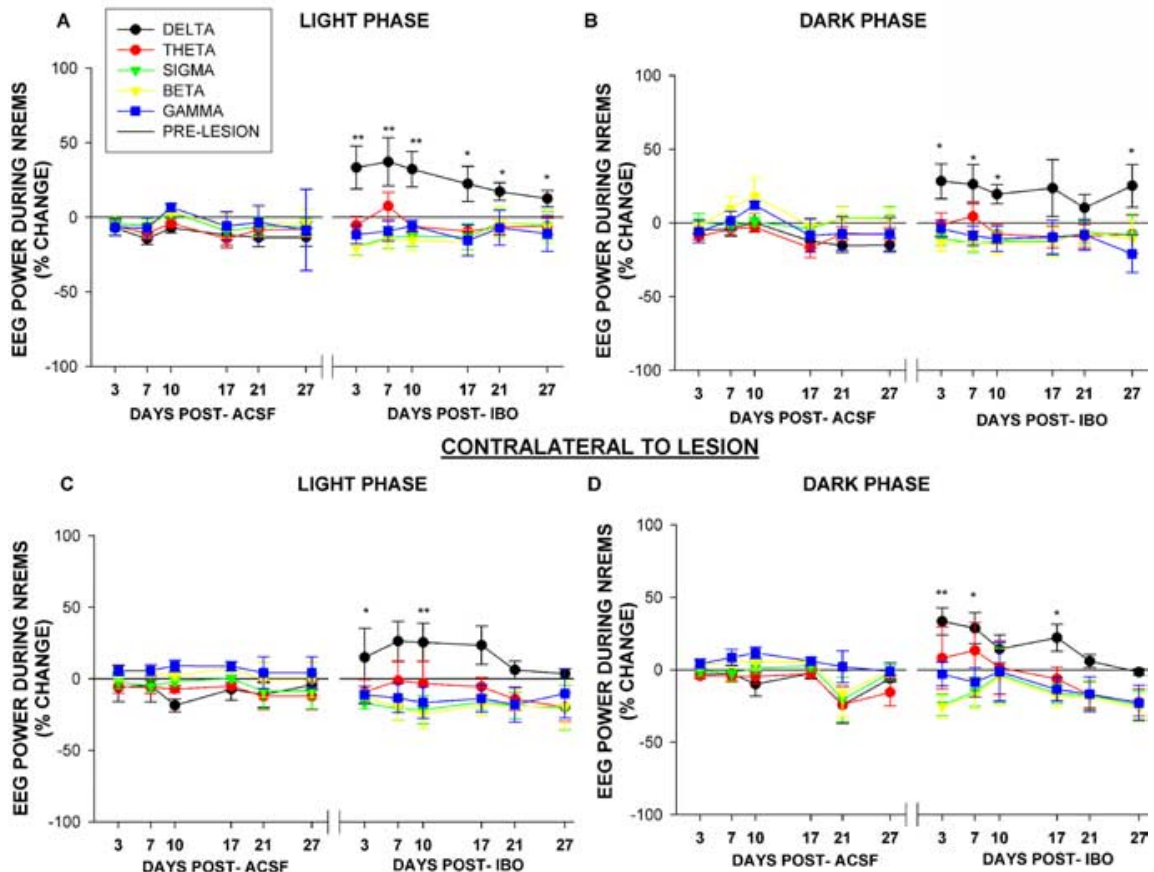

Figure 8. Time course of changes in the EEG power during NREM sleep state during light and dark phases after unilateral ibotenate injections into the nucleus basalis magnocellularis/substantia innominata. Means \pm SEM are expressed relative to prelesion baselines. $\boldsymbol{A}, \boldsymbol{B}$, Changes in the power of EEG recorded from the cortex ipsilateral to IBO lesion during the light $(\boldsymbol{A})$ and dark $(\boldsymbol{B})$ phase. $\boldsymbol{C}, \boldsymbol{D}$, Changes in the power of EEG recorded from the cortex contralateral to IBO lesion during the light $(\boldsymbol{C})$ and dark (D) phase. IBO $>$ ACSF, ${ }^{*} p<0.05,{ }^{* *} p<0.01$, Mann-Whitney $U$ test for comparison at different time points, after the significant interaction of treatment $X$ day was established with two-way ANOVA.

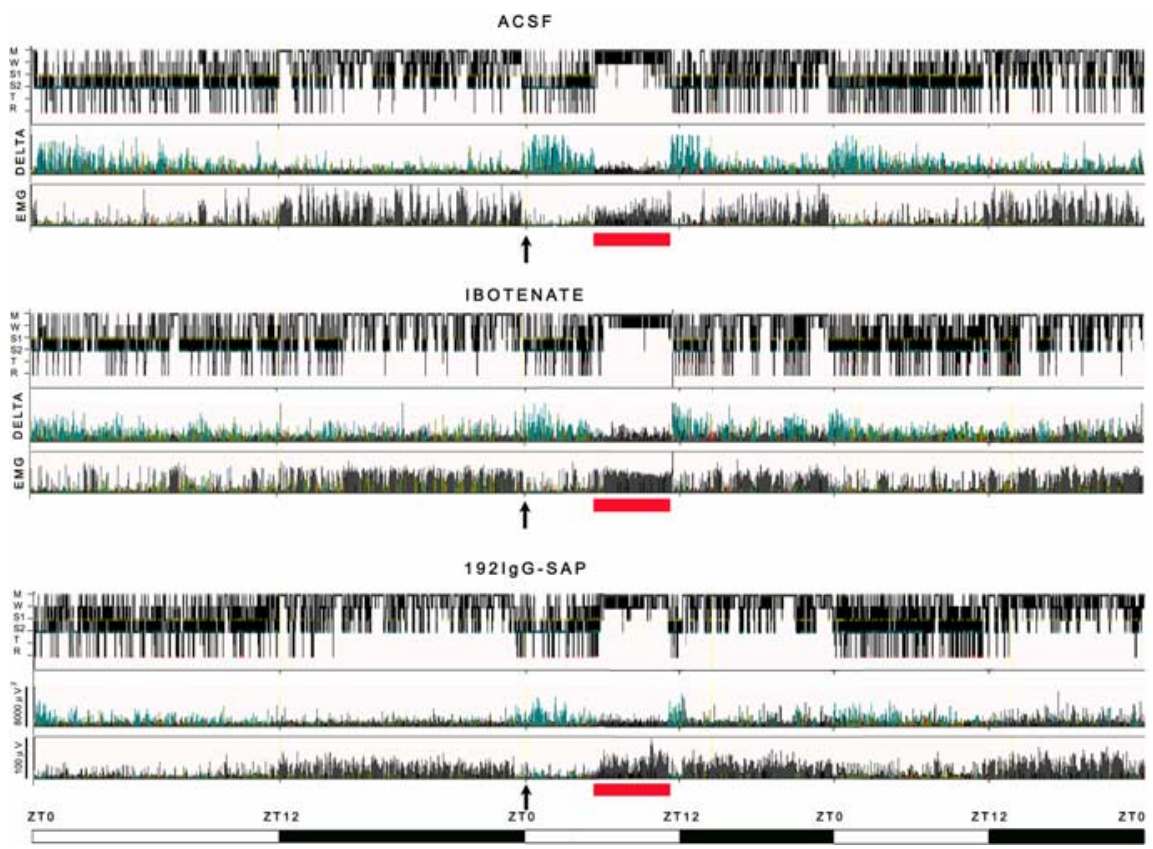

Figure 9. Examples of somnographic and polygraphic recordings from predeprivation ( $29 \mathrm{~h})$, sleep deprivation (6 h), and postdeprivation ( $37 \mathrm{~h}$ ) sessions in three representative animals injected bilaterally with ACSF (control), IB0, or 192lgG-SAP into the nucleus basalis magnocellularis/substantia innominata. The top panel of each window shows a hypnogram representing the time spent in each of 6 sleep-wake states ( $M$, movement or active wake; $W$, quiet wake; $S 1$, light slow wave sleep; $\$ 2$, deep slow wave sleep; $T$, transition to REM sleep; R, REM sleep). The second panel in each window represents the time course of delta $(1.0-4.0 \mathrm{~Hz})$ power of the EEG recorded from the left hemisphere, and the third panel shows integrated EMG. The bars at the bottom indicate 12:12 light (open bars): dark (solid bars) cycles; note a change in time scale at the end of the first dark phase (also indicated by arrows at the bottom of each window). The short bar (red) at the bottom of each window denotes the $6 \mathrm{~h}$ period of sleep deprivation which ends at ZT 11.
Effects on recovery sleep amounts

The time spent in three behavioral states after $\mathrm{SD}$ was analyzed using $6 \mathrm{~h}$ bins up to $36 \mathrm{~h}$ after SD, and additionally using $2 \mathrm{~h}$ bins for the first $12 \mathrm{~h}$. The three treatment groups showed different amounts and time courses of recovery NREM sleep over the $36 \mathrm{~h}$ post-SD recording period. In the ACSF group, NREM sleep increased during the first $6 \mathrm{~h}$ after SD by $103.7 \pm 36.8 \%$ relative to its predeprivation baseline (Fig. $11 \mathrm{~A}$ ) [two-way ANOVA with repeated measures on time ( $6 \mathrm{~h}$ bins), time $\times$ treatment, $F_{(2,10)}=2.29, p=0.021$; for first $6 \mathrm{~h}$ post-SD, $F_{(2,14)}=4.45, p=0.032$; Fisher's PLSD, IBO and SAP $<$ ACSF, $p=0.039$ and 0.013 , respectively]. The $2 \mathrm{~h}$ bin analysis indicated that the maximum increase in NREM sleep, by $167.8 \pm 84.9 \%$, occurred during the second $2 \mathrm{~h}$ period (Fig. $11 B$ ) [two-way ANOVA with repeated measures on time ( $2 \mathrm{~h}$ bins), time $\times$ treatment, $F_{(2,10)}=2.00, p=0.045$; for second $2 \mathrm{~h}$ post-SD, $F_{(2,14)}=3.79, p=0.048$; Fisher's PLSD, IBO and SAP $<$ ACSF, $p=$ 0.046 and 0.021 , respectively]. After the first $6 \mathrm{~h}$ after SD, the NREM sleep amount gradually declined to the predeprivation level, followed by a slight increase (by $21.5 \pm 6.3 \%$ of the baseline) during the latter part of the second dark phase after SD (Fig. 11A), suggesting that the presence of sleep debt carried over from the first postdeprivation day.

The IBO group showed much less recovery NREM sleep than the ACSF group, and its peak recovery was delayed by $4 \mathrm{~h}$. Thus, the IBO group showed only a $39.8 \pm$ $8.7 \%$ increase in NREM sleep during the first $6 \mathrm{~h}$ after SD (two-way ANOVA with repeated measures on time, time $X$ treatment effect, $F_{(2,10)}=2.30 ; p=0.021$; oneway ANOVA for first $6 \mathrm{~h}$ post-SD, $F_{(2,14)}=$ $4.45, p=0.031$; Fisher's PLSD, IBO < ACSF, $p=0.039)$, but a $53.8 \pm 19.5 \%$ increase in the second $6 \mathrm{~h}$ period $\left(F_{(2,14)}=\right.$ 2.37, $p=0.043$; SAP $<\mathrm{IBO}, p=0.047)$ (Fig. $11 A$ ). The $2 \mathrm{~h}$ bin analysis showed that the amount of NREM sleep peaked at $8 \mathrm{~h}$ after SD, with a $102.7 \pm 60.5 \%$ increase (Fig. $11 B$ ). As in the ACSF group, the NREM sleep amount subsequently declined to the predeprivation level during the light phase, but increased again slightly during the second dark phase, indicating that increased sleep propensity carried over from the first day after SD.

The SAP group showed the least amount of recovery NREM sleep throughout the $36 \mathrm{~h}$ recording period after SD. The NREM sleep amount during the first $6 \mathrm{~h}$ after SD was only $23.2 \pm 4.9 \%$ higher than the pre-SD baseline (Fig. 11A) (SAP < 
A

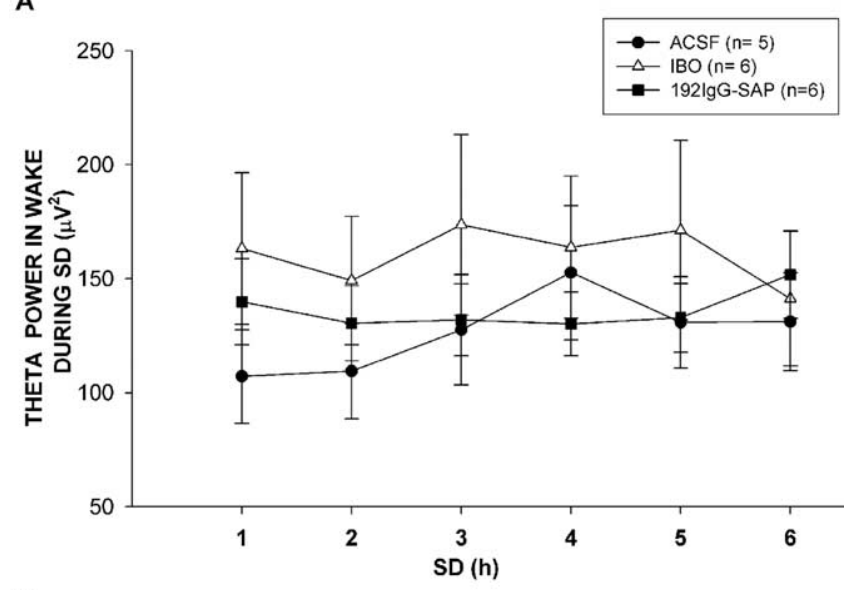

B

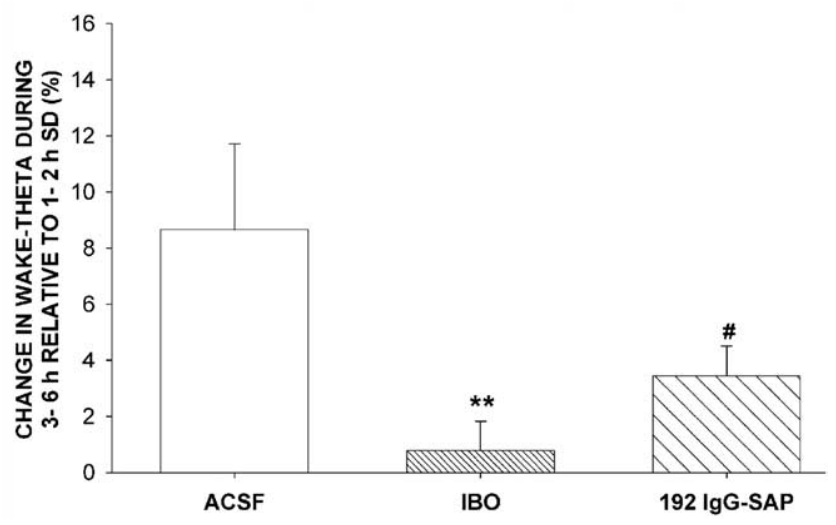

Figure 10. Time course of changes in EEG theta power during wake over a $6 \mathrm{~h} \mathrm{SD}$ period in IBO, 192lgG-SAP and ACSF groups. $A$, Time course of wake theta value (means \pm SEM) during each hour of $6 \mathrm{~h}$ of $S D$ in the three treatment groups. Note an increase in theta power in the third hour and thereafter in the ACSF group, and the absence of such increase in the IBO and SAP groups ( $p=0.0027$ for time $\times$ treatment interaction in two-way ANOVA with repeated measures). $\boldsymbol{B}$, The ratio (mean \pm SEM) of the mean change in theta during the last $4 \mathrm{~h}$ of deprivation $(3-6 \mathrm{~h})$ to the mean during first $2 \mathrm{~h}(1-2 \mathrm{~h})$. IBO $<$ ACSF, ${ }^{* *} p<0.01 ; 192 \mathrm{lgG}-$ SAP $<$ ACSF, $\# p<0.05$.

ACSF, $p=0.0125$, Fisher's PLSD). The $2 \mathrm{~h}$ bin analysis indicated that the largest increase in NREM sleep occurred during the first $2 \mathrm{~h}$ after SD, but this was only by $42.3 \pm 4.8 \%$ relative to baseline $($ Fig. $11 \mathrm{~B})$. At most other time points during the first $12 \mathrm{~h}$ post$\mathrm{SD}$, the changes in NREM sleep amount in SAP-lesioned animals were $<21 \%$ (Fig. $11 B$ ), and there was no indication of residual sleep debt on the second day.

Group comparisons relative to ACSF at several specific time points after SD provided additional information. Both SAP and IBO lesions showed reduction in recovery NREM sleep, by $76.7 \%$ (SAP) and $32.2 \%$ (IBO) relative to ACSF controls, during the first $12 \mathrm{~h}$ after SD. During the first $6 \mathrm{~h}$ period after SD, the amount of NREM sleep in the IBO and SAP groups was only 38.4 and $22.3 \%$, respectively, of the ACSF level, with no difference between the two lesion groups (Fig. $11 \mathrm{~A}$ ) (first $6 \mathrm{~h}$ post-SD, $F_{(2,14)}=4.45, p=$ 0.032; Fisher's PLSD, IBO and SAP $<$ ACSF, $p=0.039$ and 0.013 , respectively). The $2 \mathrm{~h}$ bin analysis indicated that in the second $2 \mathrm{~h}$ postdeprivation period when NREM recovery peaked in the ACSF group, the increase in NREM sleep in IBO- and SAPlesioned animals was only $17.8 \%$ and $2.5 \%$, respectively, of the amount shown by ACSF controls.

The amount of recovery REM sleep was also affected by IBO and SAP lesions, but not as greatly as for NREM sleep (Fig. 11C).
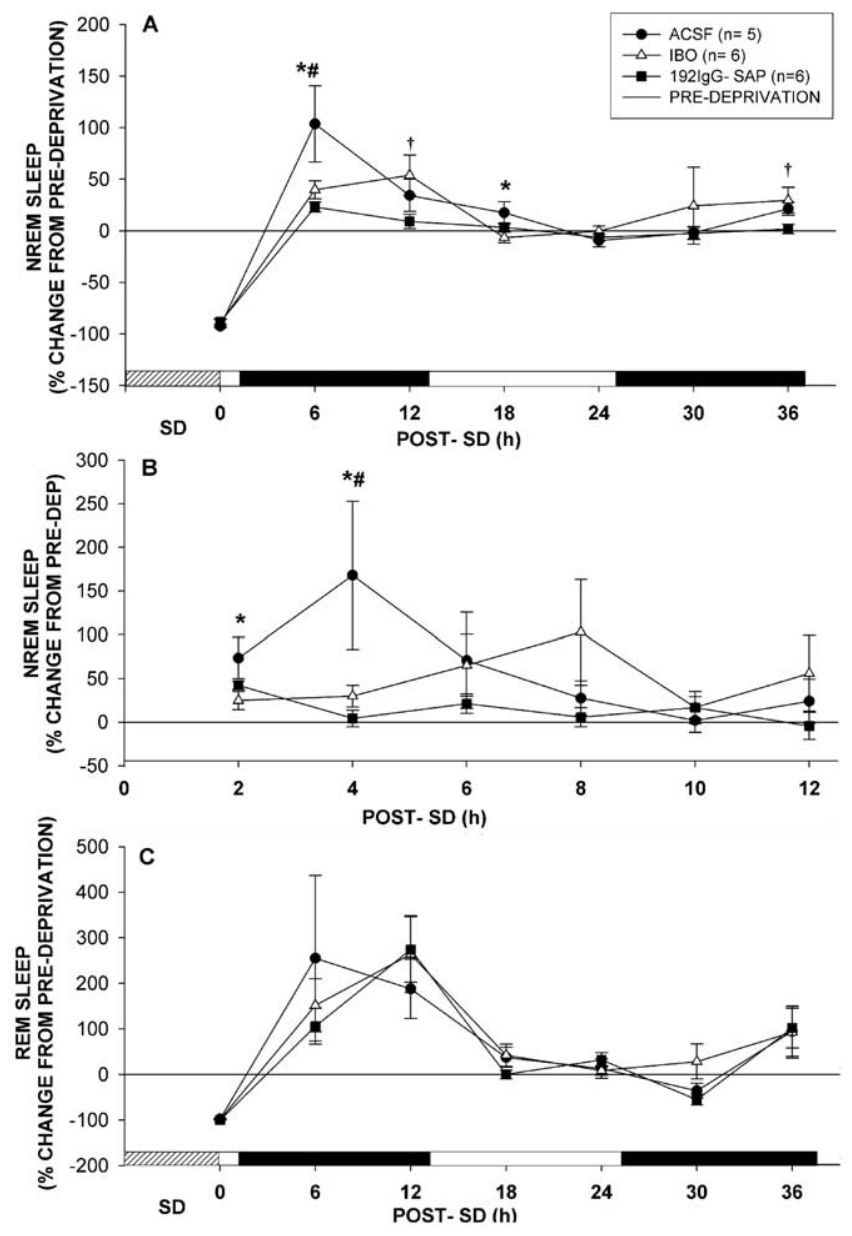

Figure 11. Time course of recovery NREM and REM sleep time changes after $6 \mathrm{~h}$ of SD in the three treatment groups. Means \pm SEM are expressed relative to respective predeprivation levels. $\boldsymbol{A}, \boldsymbol{B}$, The amounts of recovery NREM sleep times in the three treatment groups are represented as differences in percentage (mean \pm SEM) from predeprivation baselines in $6 \mathrm{~h}$ bins for the period of $36 \mathrm{~h}$ post-SD $(\boldsymbol{A})$ and in $2 \mathrm{~h}$ bins for the first $12 \mathrm{~h}$ postdeprivation $(\boldsymbol{B})$. C, The amount of recovery REM sleep time is expressed as percentage (mean \pm SEM) of the change from predeprivation baseline in the three treatment groups, and is represented in $6 \mathrm{~h} \mathrm{bins.} \mathrm{Light}$ and dark bars on $x$-axis represent light and dark phases during the recording period, and the hashed bar represents the $6 \mathrm{~h}$ SD period. 192lgG-SAP $<\mathrm{ACSF}{ }^{\#} p<0.05 ; \mathrm{IBO}<\mathrm{ACSF},{ }^{*} p<$ $0.05 ; 192 \mathrm{lgG}-\mathrm{SAP}<\mathrm{IBO},{ }^{\dagger} p<0.05$ (1-way ANOVA followed by Fisher's PLSD, after the significance was established in 2-way ANOVA for treatment $\times$ time)

Both IBO- and SAP-lesioned animals tended to show less recovery REM sleep than the ACSF group in the first $6 \mathrm{~h}$ of the postdeprivation period. This was followed by an increase in the next $6 \mathrm{~h}$ period (Fig. 11C). However, these changes were not statistically significant.

\section{Effects on recovery NREM sleep EEG}

In all three groups, EEG delta levels relative to predeprivation baseline were highest during the first $6 \mathrm{~h}$ after SD, and especially during the first $2 \mathrm{~h}$ (Fig. $12 \mathrm{~A}, \mathrm{~B}$ ). Nonetheless, the IBO and SAP groups showed lower delta levels during the first $6 \mathrm{~h}$ and more rapid decline thereafter than the ACSF group.

During the first $6 \mathrm{~h}$ period after SD, NREM delta power in the ACSF group increased by $78.6 \pm 13.3 \%$ relative to the predeprivation baseline (Fig. 12B). In contrast, IBO and SAP groups showed only a $41.2 \pm 10.8 \%$ and $50.7 \pm 8.7 \%$ increase, respectively, with the IBO group significantly lower than the ACSF group (two-way ANOVA with repeated measures on time, 

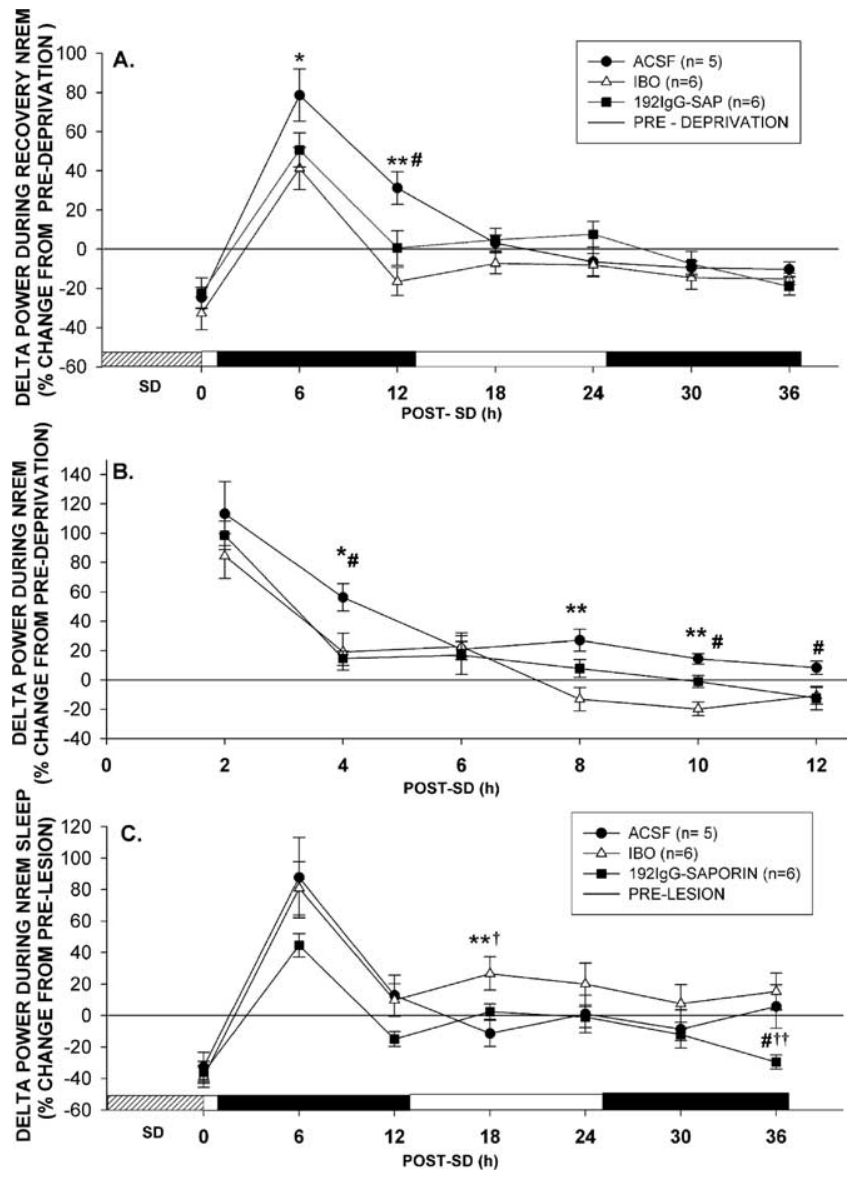

Figure 12. Time course of EEG delta power $(1-4 \mathrm{~Hz})$ changes during recovery NREM sleep after $6 \mathrm{~h}$ of $S D$. $A, B$, Delta power values (mean \pm SEM) during recovery NREM sleep are expressed in percentages of predeprivation baseline recorded on the 27th postinjection day in $6 \mathrm{~h}$ bins during $36 \mathrm{~h}$ post-SD $(\boldsymbol{A})$ and in $2 \mathrm{~h}$ bins during the first $12 \mathrm{~h}$ post-SD $(\boldsymbol{B})$. C, Delta power values (mean $\pm \mathrm{SEM}$ ) as expressed as percentages of respective prelesion baselines obtained from the recordings before ACSF, IBO, or SAP injections are shown in $6 \mathrm{~h}$ bins across the $36 \mathrm{~h}$ recovery period. IBO $<$ ACSF, ${ }^{*} p<0.05,{ }^{* *} p<0.01 ; 192 \mathrm{lgG}-\mathrm{SAP}<\mathrm{ACSF},{ }^{\#} p<0.05$; 192lgG-SAP $<\mathrm{IBO},{ }^{\dagger} p<0.05,{ }^{\dagger+} p<0.001$ (1-way ANOVA followed by Fisher's PLSD, after the significance interaction for treatment $X$ time was established in 2-way ANOVA).

time $\times$ treatment effect, $F_{(2,10)}=3.86, p=0.0001$; one-way ANOVA on first $6 \mathrm{~h}$ post-SD, $F_{(2,31)}=2.97, p=0.05$; Fisher's PLSD, IBO $<$ ACSF, $p=0.023$ ) (Fig. 12A). In the second $6 \mathrm{~h}$ period, the NREM delta power in the ACSF group remained elevated at $31.2 \pm 8.3 \%$ of the predeprivation baseline, whereas delta power values in both IBO and SAP groups had already returned to predeprivation levels, and were significantly lower than in ACSF controls $\left(F_{(2,31)}=8.03, p=0.0016\right.$; IBO $<$ ACSF, $p=0.0004$; SAP $<$ ACSF, $p=0.016$ ) (Fig. $12 A$ ). Thus, IBO and SAP lesions reduced an increase in NREM sleep delta during the first $12 \mathrm{~h}$ after SD by 77.5 and $53.3 \%$, respectively, compared with the ACSF controls. NREM delta power in the ACSF group returned to predeprivation levels in the third $6 \mathrm{~h}$ period (Fig. 12 A), and delta power values in the remainder of the $36 \mathrm{~h}$ recording period were at predeprivation levels in all three groups.

The faster return to baseline levels in both IBO and SAP groups is more evident with the $2 \mathrm{~h}$ bin data (Fig. 12B). During the first $2 \mathrm{~h}$ period after SD, the increase in NREM delta power in the IBO and SAP groups was $84.4 \pm 15.4$ and $98.5 \pm 9.6 \%$ of pre-SD baselines, respectively, which were nonsignificantly lower than the ACSF level of $113.3 \pm 21.7 \%$. During the second $2 \mathrm{~h}$ period, the delta levels in the IBO and SAP group had already declined to near predeprivation levels, whereas the delta value of the ACSF group remained high at $56.3 \pm 9.4 \%$ above the predeprivation level (two-way ANOVA, treatment effect, $F_{(2,31)}=4.63$, $p=0.017$; one-way ANOVA on second $2 \mathrm{~h}$ post-SD, $F_{(2,31)}=$ 5.26; $p=0.011$; Fisher's PLSD, IBO $<$ ACSF, $p=0.015$; $\mathrm{SAP}<$ ACSF, $p=0.011$ ).

As mentioned above, the IBO group showed an increase in delta power during baseline NREM sleep, whereas the SAP and ACSF groups showed no changes (Figs. 6, 7). We therefore evaluated the increase in delta power during recovery NREM sleep relative to prelesion baselines, instead of pre-SD baselines (Fig. $12 C)$. As expected, in the ACSF and SAP groups, the delta power values normalized to prelesion values were similar to those normalized to pre-SD baselines. However, the IBO group, which showed a smaller increase in delta power value when compared with pre-SD (Fig. 12A), now showed an increase to the level comparable with that seen in the ACSF group during the first $6 \mathrm{~h}$ period after deprivation (Fig. 12C). The IBO group continued to show higher NREM delta power values through the remainder of the recording period because of its elevated prelesion NREM delta baseline, and this increase was significant compared with the SAP and ACSF groups during the third $6 \mathrm{~h}$ postdeprivation period $\left(F_{(2,31)}=5.23 ; p=0.011 ; \mathrm{IBO}>\mathrm{ACSF}, p=0.004, \mathrm{IBO}>\right.$ SAP, $p=0.04)$.

\section{Correlations between recovery NREM sleep/delta power and loss of PARV/VAChT-immunoreactive neurons}

To assess whether the loss of either PARV + neurons or VAChT + neurons was correlated to the amount of rebound NREM sleep and the delta power during rebound NREM sleep during the first $6 \mathrm{~h}$ period after SD, Pearson's correlation coefficients were calculated between the percentage loss of PARV + or VAChT + cells in the caudal BF compared with the ACSF control (Fig. $4 B, D$, right), on one hand, and either the amount of rebound NREM sleep (Fig. $11 A$ ) or the delta power during recovery NREM sleep (Fig. 12A), on the other. For these correlations, it was not appropriate to combine the three treatment groups because, although both IBO and 192IgG-SAP lesions had similar effects on rebound sleep amounts and recovery NREM sleep delta power, IBO lesions predominantly damaged $\mathrm{PARV}+$ neurons, whereas 192IgG-SAP lesions selectively damaged VAChT + neurons. Therefore, we combined the IBO $(n=6)$ and ACSF $(n=5)$ groups to examine the correlation with PARV + cell loss, and the $\operatorname{SAP}(n=6)$ and ACSF $(n=5)$ groups for examining the correlation with VAChT + cell loss. These analyses were based on the first $6 \mathrm{~h}$ post-SD period.

The loss of either PARV + or VAChT + neurons was negatively correlated, significantly or nonsignificantly, with the amount of rebound NREM sleep (PARV: $r=-0.52, p=0.100$; VAChT: $r=-0.64, p=0.040$ ). The loss of PARV + or VAChT + neurons was also negatively correlated, significantly or nonsignificantly, with the delta power during recovery NREM sleep (PARV: $r=-0.68, p=0.023$; VAChT: $r=-0.55, p=0.081$ ). These results suggest that the loss of PARV neurons in the IBO group and the loss of cholinergic neurons in the SAP group correlated well with the decreases in rebound NREM sleep amount and rebound NREM sleep delta power.

\section{Effects of unilateral IBO lesions}

IBO-UNI lesions $(n=5)$ resulted in mostly nonsignificant decreases in recovery NREM sleep amount and in recovery NREM sleep delta power of the EEG recorded from the cortex both ipsilateral and contralateral to the lesion, compared with the prede- 
privation baseline; unilateral ACSF injections $(n=5)$ had no effect (data not shown). Significant decreases in recovery NREM sleep $\left(F_{(1,8)}=9.00, p=0.017\right.$, one-way ANOVA $)$ and recovery NREM delta on the lesioned hemisphere $\left(F_{(1,8)}=5.70, p=0.044\right.$, one-way ANOVA) were observed only during the period of 12-18 h postdeprivation (data not shown).

\section{Effects of ibotenate lesions placed outside of the basal forebrain on sleep-wake states and EEG}

In five animals, IBO lesions were localized to areas outside of the BF. These included animals with bilateral $(n=1)$ or unilateral $(n=2)$ lesions ventral to the BF that included the ventrolateral preoptic nucleus; bilateral lesions $(n=1)$ caudal to the BF that included the ventral part of the thalamus; and a unilateral lesion $(n=1)$ medial to the BF that primarily involved the lateral preoptic area. All of these animals showed a reduction in both NREM sleep and NREM delta power, with bilaterally lesioned animals showing more pronounced effects than unilaterally lesioned animals. These effects were opposite to those seen with IBO lesions of the BF. Recovery sleep was examined in the three animals with the ventral lesions at $28 \mathrm{~d}$ postlesion. After $6 \mathrm{~h}$ of SD, these animals showed an increase (by 40-90\%) in NREM sleep, and two of the three also showed an increase in NREM delta (by 76 or $89 \%$ ), which were similar to the increases observed in the ACSF group in the main study.

\section{Discussion}

We show that 192IgG-SAP lesions of the NBM/SI transiently increased spontaneous NREM sleep by up to $13 \%$ predominantly during the dark phase, with no effect on the EEG. Conversely, IBO NBM/SI lesions had no effects on sleep/wake states, but increased the EEG delta power virtually in all states (by up to $62 \%$ during NREM sleep) for $\sim 4$ weeks postlesion. Challenged with $6 \mathrm{~h}$ of SD, animals with either lesion showed a reduction in rebound NREM sleep, by 77\% (SAP) and by 32\% (IBO) relative to ACSF controls, during the first $12 \mathrm{~h}$ post-SD. During the same period, both lesions reduced rebound NREM delta power by $53 \%$ (SAP) and 78\% (IBO) compared with ACSF controls.

The selective loss of cholinergic markers after 192IgG-SAP injections into the SI/NBM, reducing caudal BF cholinergic neurons by $69 \%$ and cortical AChE staining by $84 \%$, is consistent with previous reports (Wenk et al., 1980; Heckers et al., 1994; Berntson et al., 2002). Eleven percent of PARV neurons were also lost compared with ACSF controls, probably because of nonspecific uptake of the immunotoxin, or unconjugated SAP contaminant, by neurons damaged during injection. IBO injections preferentially destroyed $43 \%$ of PARV neurons but also nonsignificantly decreased cholinergic neurons (21\%) in the caudal BF, and significantly decreased cortical AChE staining by $41 \%$. The preferential loss of noncholinergic over cholinergic BF neurons after IBO injections corroborates previous reports (Burk and Sarter, 2001; Pang et al., 2001).

This is the first study to show that IBO lesions of the NBM/SI did not affect spontaneous sleep-wake states, whereas 192IgGSAP lesions had a transient effect. The lack of IBO effect suggests that noncholinergic NBM/SI neurons are not critical for spontaneous sleep-wake states. This is unlikely to be a result of lesions being less than optimal, because the same lesions significantly altered EEG and sleep homeostasis. This IBO result contrasts with decreased sleep observed after excitotoxic lesions of more ventral forebrain regions (misplaced lesions in the present study) (Szymusiak and McGinty, 1986a), including the preoptic area (e.g., Lu et al., 2000), which contain a high concentration of sleep-active neurons (Szymusiak and McGinty, 1986b). In contrast to IBO, 192IgG-SAP lesions transiently increased NREM sleep and reduced wake predominantly during the dark phase for up to $10 \mathrm{~d}$ postlesion. The transient nature would explain the previously reported lack of effects at 16-18 d after NBM/SI injection of 192IgG-SAP (Berntson et al., 2002). The recovery may be attributable to incomplete lesions or compensation by other wake-regulatory systems unaffected by the immunotoxin. Nonetheless, the NBM/SI contains wake-active neurons (Szymusiak et al., 2000) some of which are cholinergic (Lee et al., 2005), and intra-NBM/SI microinjections of AMPA/NMDA increase wake time (Manfridi et al., 1999; Cape and Jones, 2000). Together, the present results suggest that cholinergic NBM/SI neurons play a relatively minor but supportive role in promoting behavioral wakefulness.

Although they had no effects on behavioral states, IBO lesions (bilateral $>$ unilateral) robustly increased baseline EEG delta, consistent with previous reports (Buzsaki et al., 1988; Riekkinen et al., 1990, 1991; Vanderwolf et al., 1993). We further showed that delta power increased in all states, most prominently during NREM sleep, for at least $27 \mathrm{~d}$ postlesion. The delta increase during NREM sleep was correlated with loss of PARV, but not cholinergic, neurons. Along with the lack of EEG effects of 192IgGSAP, these results strongly suggest that loss of noncholinergic, and not cholinergic, NBM/SI neurons is responsible for the EEG slowing. Decreased gamma power has been observed $\sim 2$ weeks after intra-NBM/SI 192IgG-SAP injections using $2 \mathrm{~h}$ recordings with a 95\% decrease in cortical AChE (Berntson et al., 2002). Using $24 \mathrm{~h}$ recordings with an $84 \%$ reduction in cortical AChE, we observed several trends of decreased gamma during the light phase. It is possible that cholinergic neurons are required for gamma activity associated with specific wake behaviors or cognitive performance, as they fire in close association with gamma and theta waves during active wake and REM sleep (Lee et al., 2005). Our results suggest, however, that for tonic EEG activation noncholinergic NBM/SI neurons play an important role, but cholinergic neurons probably do not. These noncholinergic neurons may include those that increase firing during cortical EEG activation (Manns et al., 2000). Releasing GABA or glutamate (Gritti et al., 1997), these neurons may block the generation of cortical slow waves either directly or indirectly via the reticular thalamic nucleus (Steriade and Buzsaki, 1990).

This is the first study to show that NBM/SI lesions with 192IgG-SAP or IBO impaired compensatory increases in NREM sleep and EEG delta power after SD, as well as the EEG measure (theta) of sleep propensity build-up during SD and wake. These effects are specific to the NBM/SI, because intraseptal hypocretin-SAP injection that damaged both cholinergic and noncholinergic neurons had no effects on post-SD homeostatic responses at 2 weeks postlesion (Gerashchenko et al., 2001). We propose that, despite their phenomenological similarities, the IBO and 192IgG-SAP effects involve different mechanisms.

We propose first that the reduced homeostatic responses after 192IgG-SAP lesions are caused by blunted adenosine accumulation in the NBM/SI during SD. Adenosine, proposed as a homeostatic sleep-promoting factor, accumulates selectively in the BF during prolonged wakefulness (Porkka-Heiskanen et al., 1997, 2002; Portas et al., 1997), and this accumulation is absent in animals with intracerebroventricular 192IgG-SAP injections (Blanco-Centurion et al., 2006). Nitric oxide is upstream to the adenosine increase (Kapas et al., 1994; Kalinchuk et al., 2003), and its production in the BF is required for rebound NREM sleep (Kalinchuk et al., 2006). Intra-BF microinjection of an adenosine 
A1 agonist induces NF- $\kappa \mathrm{B}$ nuclear translocation selectively in cholinergic neurons, and its blockade reduces recovery delta (Ramesh et al., 2007). Preliminary results indicate that intra-BF 192IgG-SAP injections attenuated both adenosine increase and recovery sleep (Kalinchuk et al., 2005). These findings suggest that the adenosine build-up in the NBM/SI during SD is compromised in 192IgG-SAP-lesioned animals. Adenosine inhibits cholinergic and certain noncholinergic $\mathrm{BF}$ neurons through $\mathrm{A}_{1}$ receptor activation (Alam et al., 1999; Thakkar et al., 2003; Basheer et al., 2004; Arrigoni et al., 2006). Intra-BF infusion of a selective $A_{1}$ agonist remains effective in inducing NREM sleep after intracerebroventricular injections of 192IgG-SAP (Blanco-Centurion et al., 2006). These findings suggest that the low levels of adenosine in 192IgG-SAP-lesioned animals could only partially inhibit noncholinergic BF neurons that promote wake and EEG activation, thereby failing to fully initiate BF mechanisms that promote recovery sleep and delta. This interpretation is consistent with the report of a blunted increase in recovery NREM delta (Wisor et al., 2005) in a transgenic mouse model of Alzheimer's disease showing loss of cholinergic BF neurons (Masliah et al., 2001) and cortical cholinergic synapses (Luth et al., 2003).

We also propose that sleep homeostasis impairment after IBO lesions of the NBM/SI results from damage to noncholinergic neurons that detect and signal sleep need. These neurons probably include wake-active neurons (Szymusiak et al., 2000) and sleep-active neurons, some of which are GABAergic (Modirrousta et al., 2004) and might be interneurons containing GABA, NPY, or somatostatin (Zaborszky and Duque, 2000). Interestingly, recovery NREM delta of IBO-lesioned animals increased to about the same level as in ACSF controls, but relative increase was smaller because their baselines were elevated. Less accumulation of sleep drive but increased baseline delta power is not consistent with the current hypothesis of the delta power as a measure of sleep propensity (Borbely and Achermann, 2005). Blunted increases in delta and recovery sleep after SD occur also in aged rats (Shiromani et al., 2000), which, however, show lower baseline delta power, consistent with the delta power hypothesis. The significance of the increased baseline delta in all states in IBO animals for sleep homeostasis remains unclear.

Several studies have used intracerebroventricular injection of 192IgG-SAP to examine its effects on spontaneous sleep and sleep homeostasis. The effects on total sleep/wake amounts appear to be short lasting or absent (Bassant et al., 1995; Kapas et al., 1996; Gerashchenko et al., 2001; Blanco-Centurion et al., 2006). Starkly discrepant from the present NBM/SI injection results are the normal homeostatic responses to $6 \mathrm{~h}$ of SD after complete depletion of both rostral and presumably caudal BF cholinergic neurons (Blanco-Centurion et al., 2006). Hypocretin-SAP injections into the medial septum had no effects on spontaneous or recovery sleep (Gerashchenko et al., 2001). However, inactivation of the septohippocampal system potentiates general anesthesia (Ma et al., 2002), and the sedative action of general anesthetics may involve endogenous sleep-promoting pathways (Nelson et al., 2002). It is conceivable that selective loss of septal cholinergic neurons might promote recovery sleep, perhaps by disinhibiting adjacent preoptic neurons known to be involved in sleep homeostasis (Gvilia et al., 2006). This possible role of septal cholinergic neurons antagonistic to the caudal cholinergic neurons remains to be investigated.

In conclusion, the present results suggest that cholinergic and noncholinergic neurons in the NBM/SI are primarily involved in spontaneous behavioral and EEG activation, respectively, whereas both play an important role, probably through different mechanisms, in recovery sleep and increased EEG delta power after SD. These results also suggest that spontaneous sleep and homeostatic sleep are regulated through overlapping but different mechanisms within the NBM/SI.

\section{References}

Alam MN, Szymusiak R, Gong H, King J, McGinty D (1999) Adenosinergic modulation of rat basal forebrain neurons during sleep and waking: neuronal recording with microdialysis. J Physiol 521:679-690.

Arrigoni E, Chamberlin NL, Saper CB, McCarley RW (2006) Adenosine inhibits basal forebrain cholinergic and noncholinergic neurons in vitro. Neuroscience 140:403-413.

Basheer R, Strecker RE, Thakkar MM, McCarley RW (2004) Adenosine and sleep-wake regulation. Prog Neurobiol 73:379-396.

Bassant MH, Apartis E, Jazat-Poindessous FR, Wiley RG, Lamour YA (1995) Selective immunolesion of the basal forebrain cholinergic neurons: effects on hippocampal activity during sleep and wakefulness in the rat. Neurodegeneration 4:61-70.

Berntson GG, Shafi R, Sarter M (2002) Specific contributions of the basal forebrain corticopetal cholinergic system to electroencephalographic activity and sleep/waking behaviour. Eur J Neurosci 16:2453-2461.

Blanco-Centurion C, Xu M, Murillo-Rodriguez E, Gerashchenko D, Shiromani AM, Salin-Pascual RJ, Hof PR, Shiromani PJ (2006) Adenosine and sleep homeostasis in the basal forebrain. J Neurosci 26:8092-8100.

Borbely AA, Achermann P (2005) Sleep homeostasis and models of sleep regulation. In: Principles and practice of sleep medicine (Kryger MH, Roth T, Dement WC, eds), pp 405-417. Philadelphia: Elsevier Saunders.

Burk JA, Sarter M (2001) Dissociation between the attentional functions mediated via basal forebrain cholinergic and GABAergic neurons. Neuroscience 105:899-909.

Buzsaki G, Bickford RG, Ponomareff G, Thal LJ, Mandel R, Gage FH (1988) Nucleus basalis and thalamic control of neocortical activity in the freely moving rat. J Neurosci 8:4007-4026.

Cahill JF, Baxter MG (2001) Cholinergic and noncholinergic septal neurons modulate strategy selection in spatial learning. Eur J Neurosci 14:1856-1864.

Cape EG, Jones BE (2000) Effects of glutamate agonist versus procaine microinjections into the basal forebrain cholinergic cell area upon gamma and theta EEG activity and sleep-wake state. Eur J Neurosci $12: 2166-2184$.

Detari L, Rasmusson DD, Semba K (1999) The role of basal forebrain neurons in tonic and phasic activation of the cerebral cortex. Prog Neurobiol 58:249-277.

Deurveilher S, Lo H, Murphy JA, Burns J, Semba K (2006) Differential c-Fos immunoreactivity in arousal-promoting cell groups following systemic administration of caffeine in rats. J Comp Neurol 498:667-689.

Gerashchenko D, Salin-Pascual R, Shiromani PJ (2001) Effects of hypocretin-saporin injections into the medial septum on sleep and hippocampal theta. Brain Res 913:106-115.

Gritti I, Mainville L, Mancia M, Jones BE (1997) GABAergic and other noncholinergic basal forebrain neurons, together with cholinergic neurons, project to the mesocortex and isocortex in the rat. J Comp Neurol 383:163-177.

Gvilia I, Xu F, McGinty D, Szymusiak R (2006) Homeostatic regulation of sleep: a role for preoptic area neurons. J Neurosci 26:9426-9433.

Heckers S, Ohtake T, Wiley RG, Lappi DA, Geula C, Mesulam MM (1994) Complete and selective cholinergic denervation of rat neocortex and hippocampus but not amygdala by an immunotoxin against the p75 NGF receptor. J Neurosci 14:1271-1289.

Holschneider DP, Leuchter AF, Walton NY, Scremin OU, Treiman DM (1997) Changes in cortical EEG and cholinergic function in response to NGF in rats with nucleus basalis lesions. Brain Res 765:228-237.

Jones BE (2005) From waking to sleeping: neuronal and chemical substrates. Trends Pharmacol Sci 26:578-586.

Kalinchuk A, Stenberg D, Porkka-Heiskanen T (2005) On the role of the basal forebrain cholinergic neurons in regulation of recovery sleep. Sleep 28:Abstr Suppl A21.

Kalinchuk AV, Urrila AS, Alanko L, Heiskanen S, Wigren HK, Suomela M, Stenberg D, Porkka-Heiskanen T (2003) Local energy depletion in the basal forebrain increases sleep. Eur J Neurosci 17:863-869.

Kalinchuk AV, Lu Y, Stenberg D, Rosenberg PA, Porkka-Heiskanen T (2006) 
Nitric oxide production in the basal forebrain is required for recovery sleep. J Neurochem 99:483-498.

Kapas L, Fang J, Krueger JM (1994) Inhibition of nitric oxide synthesis inhibits rat sleep. Brain Res 664:189-196.

Kapas L, Obal Jr F, Book AA, Schweitzer JB, Wiley RG, Krueger JM (1996) The effects of immunolesions of nerve growth factor-receptive neurons by 192 IgG-saporin on sleep. Brain Res 712:53-59.

Kleiner S, Bringmann A (1996) Nucleus basalis magnocellularis and pedunculopontine tegmental nucleus: control of the slow EEG waves in rats. Arch Ital Biol 134:153-167.

Lancel M, Kerkhof GA (1989) Effects of repeated sleep deprivation in the dark- or light-period on sleep in rats. Physiol Behav 45:289-297.

Lee MG, Hassani OK, Alonso A, Jones BE (2005) Cholinergic basal forebrain neurons burst with theta during waking and paradoxical sleep. J Neurosci 25:4365-4369.

Lu J, Greco MA, Shiromani P, Saper CB (2000) Effect of lesions of the ventrolateral preoptic nucleus on NREM and REM sleep. J Neurosci 20:3830-3842.

Luth HJ, Apelt J, Ihunwo AO, Arendt T, Schliebs R (2003) Degeneration of beta-amyloid-associated cholinergic structures in transgenic APP SW mice. Brain Res 977:16-22.

Ma J, Shen B, Stewart LS, Herrick IA, Leung LS (2002) The septohippocampal system participates in general anesthesia. J Neurosci 22:RC200(1-6).

Manfridi A, Brambilla D, Mancia M (1999) Stimulation of NMDA and AMPA receptors in the rat nucleus basalis of Meynert affects sleep. Am J Physiol 277:R1488-R1492.

Manns ID, Alonso A, Jones BE (2000) Discharge profiles of juxtacellularly labeled and immunohistochemically identified GABAergic basal forebrain neurons recorded in association with the electroencephalogram in anesthetized rats. J Neurosci 20:9252-9263.

Masliah E, Rockenstein E, Veinbergs I, Sagara Y, Mallory M, Hashimoto M, Mucke L (2001) Beta-amyloid peptides enhance alpha-synuclein accumulation and neuronal deficits in a transgenic mouse model linking Alzheimer's disease and Parkinson's disease. Proc Natl Acad Sci USA 98:12245-12250.

Massimini M, Huber R, Ferrarelli F, Hill S, Tononi G (2004) The sleep slow oscillation as a traveling wave. J Neurosci 24:6862-6870.

Modirrousta M, Mainville L, Jones BE (2004) Gabaergic neurons with alpha2-adrenergic receptors in basal forebrain and preoptic area express c-Fos during sleep. Neuroscience 129:803-810.

Neckelmann D, Ursin R (1993) Sleep stages and EEG power spectrum in relation to acoustical stimulus arousal threshold in the rat. Sleep 16:467-477.

Nelson LE, Guo TZ, Lu J, Saper CB, Franks NP, Maze M (2002) The sedative component of anesthesia is mediated by $\mathrm{GABA}_{\mathrm{A}}$ receptors in an endogenous sleep pathway. Nat Neurosci 5:979-984.

Pang KC, Nocera R, Secor AJ, Yoder RM (2001) GABAergic septohippocampal neurons are not necessary for spatial memory. Hippocampus 11:814-827.

Paxinos G, Watson C (1998) The rat brain in stereotaxic coordinates, Ed 4. San Diego: Academic.

Pizzo DP, Waite JJ, Thal LJ, Winkler J (1999) Intraparenchymal infusions of 192 IgG-saporin: development of a method for selective and discrete lesioning of cholinergic basal forebrain nuclei. J Neurosci Methods 91:9-19.

Porkka-Heiskanen T, Strecker RE, Thakkar M, Bjorkum AA, Greene RW, McCarley RW (1997) Adenosine: a mediator of the sleep-inducing effects of prolonged wakefulness. Science 276:1265-1268.

Porkka-Heiskanen T, Alanko L, Kalinchuk A, Stenberg D (2002) Adenosine and sleep. Sleep Med Rev 6:321-332.

Portas CM, Thakkar M, Rainnie DG, Greene RW, McCarley RW (1997) Role of adenosine in behavioral state modulation: a microdialysis study in the freely moving cat. Neuroscience 79:225-235.
Ramesh V, Thatte HS, McCarley RW, Basheer R (2007) Adenosine and sleep deprivation promote NF-kappaB nuclear translocation in cholinergic basal forebrain. J Neurochem 100:1351-1363.

Riekkinen Jr P, Sirvio J, Riekkinen P (1990) Relationship between the cortical choline acetyltransferase content and EEG delta-power. Neurosci Res 8:12-20.

Riekkinen Jr P, Sirvio J, Riekkinen M, Riekkinen P (1991) EEG changes induced by acute and chronic quisqualic or ibotenic acid nucleus basalis lesions are stabilized by tacridine. Brain Res 559:304-308.

Semba K (2000) Multiple output pathways of the basal forebrain: organization, chemical heterogeneity, and roles in vigilance. Behav Brain Res 115:117-141.

Semba K, Fibiger HC (1989) Organization of central cholinergic systems. Prog Brain Res 79:37-63.

Semba K, Reiner PB, McGeer EG, Fibiger HC (1988) Non-cholinergic basal forebrain neurons project to the contralateral basal forebrain in the rat. Neurosci Lett 84:23-28.

Shiromani PJ, Lu J, Wagner D, Thakkar J, Greco MA, Basheer R, Thakkar M (2000) Compensatory sleep response to $12 \mathrm{~h}$ wakefulness in young and old rats. Am J Physiol Regul Integr Comp Physiol 278:R125-133.

Steriade M, Buzsaki G (1990) Parallel activation of thalamic and cortical neurons by brainstem and basal forebrain cholinergic systems. In: Brain cholinergic systems (Biesold D, ed), pp 3-63. New York: Oxford UP.

Szymusiak R, McGinty D (1986a) Sleep suppression following kainic acidinduced lesions of the basal forebrain. Exp Neurol 94:598-614.

Szymusiak R, McGinty D (1986b) Sleep-related neuronal discharge in the basal forebrain of cats. Brain Res 370:82-92.

Szymusiak R, Alam N, McGinty D (2000) Discharge patterns of neurons in cholinergic regions of the basal forebrain during waking and sleep. Behav Brain Res 115:171-182.

Tago H, Kimura H, Maeda T (1986) Visualization of detailed acetylcholinesterase fiber and neuron staining in rat brain by a sensitive histochemical procedure. J Histochem Cytochem 34:1431-1438.

Thakkar MM, Winston S, McCarley RW (2003) A1 receptor and adenosinergic homeostatic regulation of sleep-wakefulness: effects of antisense to the Al receptor in the cholinergic basal forebrain. I Neurosci 23:4278-4287.

Tobler I, Borbely AA (1990) The effect of 3-h and 6-h sleep deprivation on sleep and EEG spectra of the rat. Behav Brain Res 36:73-78.

Vanderwolf CH, Raithby A, Snider M, Cristi C, Tanner C (1993) Effects of some cholinergic agonists on neocortical slow wave activity in rats with basal forebrain lesions. Brain Res Bull 31:515-521.

Vyazovskiy V, Achermann P, Borbely AA, Tobler I (2004) Interhemispheric coherence of the sleep electroencephalogram in mice with congenital callosal dysgenesis. Neuroscience 124:481-488.

Vyazovskiy VV, Tobler I (2005) Theta activity in the waking EEG is a marker of sleep propensity in the rat. Brain Res 1050:64-71.

Wenk GL, Stoehr JD, Quintana G, Mobley S, Wiley RG (1994) Behavioral, biochemical, histological, and electrophysiological effects of 192 IgGsaporin injections into the basal forebrain of rats. J Neurosci 14:5986-5995.

Wenk H, Bigl V, Meyer U (1980) Cholinergic projections from magnocellular nuclei of the basal forebrain to cortical areas in rats. Brain Res 2:295-316.

Wisor JP, Edgar DM, Yesavage J, Ryan HS, McCormick CM, Lapustea N, Murphy Jr GM (2005) Sleep and circadian abnormalities in a transgenic mouse model of Alzheimer's disease: a role for cholinergic transmission. Neuroscience 131:375-385.

Zaborszky L, Duque A (2000) Local synaptic connections of basal forebrain neurons. Behav Brain Res 115:143-158.

Zaborszky L, Pang K, Somogyi J, Nadasdy Z, Kallo I (1999) The basal forebrain corticopetal system revisited. Ann N Y Acad Sci 877:339-367. 